RUNNING HEAD: Are different risk factors associated with moderate and severe stalking violence?

Are different risk factors associated with moderate and severe stalking violence? Examining factors from the integrated theoretical model of stalking violence

Carleen M. Thompson, PhD, Susan M. Dennison, PhD, and Anna L. Stewart, PhD

School of Criminology and Criminal Justice, Griffith University, Brisbane Australia

Authors' Note

We would like to thank the participants who kindly participated in this research. This research was funded by an Australian Commonwealth Government scholarship, Australian Postgraduate Award. All correspondence should be addressed to Carleen M. Thompson, School of Criminology and Criminal Justice, Griffith University, Mt Gravatt Campus QLD Australia 4111; email: $\underline{\text { C.Thompson@griffith.edu.au. }}$ 
RUNNING HEAD: Are different risk factors associated with moderate and severe stalking violence?

\begin{abstract}
This study investigated risk factors from the integrated theoretical model of stalking violence (ITMSV) with 703 participants classified as relational stalkers from South-East Queensland (Australia). Participants completed a self-report perpetration questionnaire assessing (a) relational stalking (b) stalking violence (no/moderate/severe) and (c) predisposing (sociocultural, psychological, historical) and contextual (intentions, triggering events, disinhibitors) risk factors. Findings supported key propositions from the ITMSV. Severely violent stalkers were characterized by a greater number, and more severe types, of predisposing factors than moderately violent or non-violent stalkers. The importance of contextual factors was supported in relation to both moderate and severe stalking violence. Combining predisposing and contextual factors resulted in strong predictions of both moderate and severe stalking violence. These findings highlight the pertinence of differentiating moderate and severe stalking violence and combining predisposing and contextual factors in assessments of risk.
\end{abstract}

Key words: stalking, violence, risk factors, theory, model, severe violence, moderate violence 


\section{Are Different Risk Factors Associated with Moderate and Severe Stalking Violence?}

\section{Examining Factors from the Integrated Theoretical Model of Stalking Violence}

Violence occurs in an average of $30 \%$ to $40 \%$ of stalking cases (Rosenfeld, 2004; Spitzberg \& Cupach, 2007). In these cases, targets endure the psychological harm associated with stalking in addition to the psychological and physical harm associated with physical violence, with potentially debilitating repercussions (Pathe \& Mullen, 1997; Thomas, Purcell, Pathe, \& Mullen, 2008). Despite this, little is known about the causes of stalking violence. The sparse knowledge accumulated is primarily derived from atheoretical investigations of risk factors with limited discussion of how these risk factors influence stalking violence and under what conditions. Moreover, despite some evidence that risk factors may vary across the severity of stalking violence (James \& Farnham 2003; Sheridan \& Roberts, 2011), few studies have examined whether different risk factors are associated with moderate and severe stalking violence. To address these limitations, the present research examines the utility of risk factors proposed in the integrated theoretical model of stalking violence (ITMSV; Thompson, 2009) across moderate and severe violence to (a) investigate the independent effect of each theoretically-driven risk factor and (b) explore what combination of risk factors best predicts moderate and severe stalking violence.

\section{Stalking Violence: A Review of the Literature}

Current understanding of the causes of stalking violence is almost exclusively derived from atheoretical investigations of risk factors in samples of forensic or forensic psychiatric cases. Risk factors that have been proposed in this research include: threats, ex-intimate relationship, criminal history, history of violence, history of domestic violence, absence of psychosis, history of substance abuse, personality disorders, and revenge motives (see Table 1). Although all of these risk factors have received some support, the findings for many of these factors vary across studies. For example, there are mixed findings for criminal history, history of violence, history of domestic violence, history of substance abuse, revenge motives, 
RUNNING HEAD: Are different risk factors associated with moderate and severe stalking violence?

and personality disorder. Therefore it is difficult to draw conclusions regarding the utility of these factors for predicting stalking violence. For other risk factors, there is quite consistent support across stalking violence research. For example, threats and prior intimate relationship have been examined in more than a dozen studies, and have almost always been found to be significant predictors of stalking violence. However, even these well-established risk factors have reasonably high rates of false positives and/or false negatives (e.g., in one study $45 \%$ of ex-intimate stalkers were not violent and $60 \%$ of violent stalkers were not ex-intimate stalkers; Thomas et al., 2008). This suggests that other variables may be important in predicting when threats and former intimate relationships are likely to lead to violence.

It is possible that conflicting findings and high rates of predictive error are partially associated with methodological variations and/or limitations and the failure of most researchers to differentiate moderate and severe violence. To illustrate, several risk factors with inconsistent findings are typically examined as composite variables (e.g., drug and alcohol abuse are combined as substance abuse, all personality disorders are combined, and histories of violence are typically measured using official records that do not differentiate between the severity or type of violence). However, it is possible that stalking violence is associated with some components of these risk factors, but not others (e.g., Roberts, 2005 found that drug abuse was related to violence but alcohol abuse was not). Additionally, the vast majority of research on stalking violence solely investigates the likelihood of violence without differentiating the severity of violence. However, if a particular risk factor is associated with either moderate or severe violence only, an omnibus classification of stalking violence may obscure the results. Consistent with this, preliminary research suggests that there may be several differences between risk factors associated with severe stalking violence and risk factors typically reported for stalking violence, including criminal history (James \& Farnham, 2003), history of violence (James \& Farnham, 2003; Sheridan \& Roberts, 2011), 
RUNNING HEAD: Are different risk factors associated with moderate and severe stalking violence?

substance abuse (Brewster, 2000; James \& Farnham, 2003; Sheridan \& Roberts, 2011), and absence of psychosis (Farnham, James, \& Cantrell, 2000).

Some of the above issues may have arisen due to the atheoretical nature of existing research, whereby there has been an absence of theoretical frameworks to guide the selection of risk factors, define risk factors, and propose the conditions under which these factors may be relevant. The integration of risk factors into a theoretical framework has the potential to foster a more comprehensive understanding of (a) how risk and protective factors exert their influence and under what conditions (b) which variables are likely to be important across moderate and severe violence (c) which risk factors could be combined in composite variables and which factors should not, or which risk factors from composite variables may be important; and (d) the identification of additional risk and protective factors. Due to the potential benefits of a theoretical framework for addressing the limitations of existing stalking violence research, this research examines risk factors derived from Thompson's (2009) ITMSV.

\section{Thompson's (2009) Integrated Theoretical Model of Stalking Violence}

The ITMSV is the first theoretical model specifically developed to explain the etiology and escalation of stalking violence. It integrates multiple levels of analysis and differentiates amongst the severity of stalking violence. This model (a) integrates theoretical propositions associated with existing stalking violence risk factors in an effort to explain how these factors may exert their influence and (b) draws from theories of domestic violence (e.g., a need for control; Follingstad, Bradley, Helff, \& Laughlin, 2002), sexual violence (e.g., the integrated theory of the etiology of sexual offending; Marshall \& Barbaree, 1990), and general interpersonal violence (e.g., developmental origins of physical aggression; Tremblay \& Nagin, 2005) to propose new theoretically-based risk factors. Due to the complexity of the model, only the key components will be reviewed in this paper. Readers should consult Thompson 
RUNNING HEAD: Are different risk factors associated with moderate and severe stalking violence?

(2009) for a more detailed description. The primary elements of the ITMSV are displayed in Figure 1.

\section{FIGURE 1 ABOUT HERE}

The ITMSV proposes that stalkers, like all humans, have a biological propensity for violence (Tremblay \& Nagin, 2005), particularly under circumstances such as conflict, anger or frustration of goals/rewards, and romantic rejection (e.g., Caplan, Vespo, Pedersen, \& Hay, 1991; Tremblay \& Nagin, 2005; Zahn-Waxler, Friedman, Cole, Mizuta, \& Hiruma, 1996). As stalking typically occurs in these contexts, stalkers need to have learned to inhibit such violence and to employ alternative coping strategies to refrain from violence. A stalker's ability to do so is either strengthened or weakened by various sociocultural, psychological, and historical factors (i.e., predisposing factors).

\section{Predisposing factors: Sociocultural, psychological, and historical factors.}

Sociocultural factors have an important role in socializing individuals to inhibit their propensity for violence and to learn alternative coping strategies. Specifically, violent social networks (i.e., violent family and friends; Foshee, Bauman, \& Linder, 1999; Bernburg \& Thorlindsson, 1999) and violent sociocultural beliefs (e.g., violent relational entitlement; Cassidy, 1995; Gilchrist, 2009) may reduce a stalker’s capacity or inclination to refrain from using violence. These sociocultural environments are less likely to teach stalkers that violence is inappropriate and should be restrained in certain contexts and are less likely to foster the development of alternative coping strategies in these contexts (e.g., dealing with stressful situations like rejection and break ups). Together, these factors are likely to predispose a stalker to violence.

Psychological factors, such as insecure adult attachments (McClellan \& Killeen, 2000), borderline personality traits (Goldenson, Geffner, Foster, \& Clipson, 2007), narcissistic 
personality traits (Bushman \& Baumeister, 1998), and a need for control (Follingstad et al., 2002), may impede a stalker's capacity to refrain from using violence. These psychological characteristics influence individuals’ vulnerability and reactions to rejection, humiliation, and interpersonal conflict. These characteristics may also weaken their ability to regulate their emotions and limit their capacity for behavioral restraint, thus stalkers with these psychological characteristics may respond to these types of situations with violence.

Sociocultural and psychological factors are relatively stable over time and are applicable across contexts. Consequently, these factors are likely to have influenced whether stalkers have engaged in violence in the past (i.e., historical factors). Previous uses of violence may also reinforce the use of violence as a coping strategy or conflict resolution technique (Patterson, Shaw, Snyder, \& Yoerger, 2001) and alternative coping strategies may be less readily available (Indermaur, 1996). Therefore, stalkers with a history of violence may be more likely to perpetrate violence in the future. Moreover, the severity of stalking violence may be related to the severity of violence perpetrated in the past, whereby stalkers with a history of severe violence may be more likely to perpetrate severe stalking violence, whereas stalkers with a history of moderate violence only may be more likely to perpetrate moderate stalking violence but not necessarily severe stalking violence (i.e., continuity of violence; Holtzworth-Munroe \& Meehan, 2004).

\section{Contextual factors: Intentions, triggering events, opportunities, and disinhibitors.}

Despite the capacity for predisposing variables to weaken a stalker's ability to refrain from using violence, contextual variables are likely to determine if, when, and where violence occurs. Violence is unlikely to occur if the stalker has no intention to inflict violence against the target or a third party (e.g., revenge motives; Wilkinson \& Hamerschlag, 2005). These intentions may be pre-meditated (e.g., expressed as threats of violence; Campbell et al., 2003) or they may be an instantaneous response to a situation. Therefore, intentions can fluctuate. 
RUNNING HEAD: Are different risk factors associated with moderate and severe stalking violence?

Another contextual factor that may be related to these fluctuations is triggering events. Triggering events are events or circumstances that may evoke negative emotions or stress in individuals and subsequently violent retaliation (Meloy, 1997; Wortley, 2001), for example arguments, confrontations, and the issuance of protection orders. Here, the stalker encounters a stressful situation that they do not know how to deal with, reducing their ability to refrain from violence. Triggering events may either engender violent motives in individuals who had not intended to perpetrate violence, or they may augment individuals' existing intentions to perpetrate violence (Cornish \& Clarke, 2003).

Even if a stalker intends to inflict violence against the target, opportunities for violence must exist for violence to ensue (e.g., accessibility to the victim; Cohen \& Felson, 1979), thus determining when and where violence occurs. The methods of intrusion utilized by stalkers may provide more or less opportunities for violence or triggering events to occur. If disinhibitors that reduce the stalkers' social and moral inhibitions are present (e.g., alcohol or drug use or intense emotions like anger, rage or jealousy; McKenry, Julian, \& Gavazzi, 1995; McMurran, 2007; Wang \& Diamond, 1999), their capacity to refrain from violence may be even further diminished.

Severity of violence. According to the ITMSV, different factors are associated with moderate violence (e.g., push or shove, slap) and severe violence (e.g., beat up, choke, use a knife or gun). Here, severity is defined according to the Revised Conflict Tactics Scale (CTS2; Straus, Hamby, Boney-McCoy, \& Sugarman, 1996) and the probable severity of the consequences of the behavior. The ITMSV posits that contextual factors determine the circumstances under which violence (both moderate and severe) does or does not occur. However, the severity of violence that ensues in these contexts is primarily determined by predisposing factors. Those stalkers with numerous and severe types of predisposing factors are likely to present a risk of severe violence. These predisposing variables may include a sociocultural environment conducive to severe violence (i.e., severe violence in one's family 
RUNNING HEAD: Are different risk factors associated with moderate and severe stalking violence?

of origin, violent friends, sociocultural beliefs supportive of violence), psychological problems (i.e., narcissism, borderline personality features or a need for control), and a history of severe violence. Consistent with this, a number of predisposing factors have been empirically associated with severe violence but were either (a) unrelated to moderate violence or (b) associated with moderate violence to a lesser extent (e.g., violent families of origin; Thompson, Saltzman, \& Johnson, 2001; personality disorders; Runge, 2005; need for control; Follingstad, Bradley, Laughlin, \& Burke, 1999; and substance abuse; Pan, Neidig, \& O’Leary, 1994).

On the other hand, stalkers with few and moderate types of predisposing factors (e.g., a history of moderate violence along with few other predisposing factors) are likely to present a risk of moderate stalking violence. In this respect, moderate stalking violence may be less associated with stalkers' underlying predispositions for violence than severe stalking violence. Instead, moderate stalking violence may be primarily associated with contextual factors that either triggered violence or created situations that the stalker was ill-equipped to deal with. Similar differences across the severity of violence and the severity of criminal behavior have been proposed in the intimate partner violence literature (e.g., Follingstad et al., 1999; Follingstad et al., 2002) as well as typologies proposed for domestic violence (HoltzworthMunroe \& Stuart, 1994), general criminal behavior (Cornish \& Clarke, 2003), and adolescent offending (e.g., Moffitt, 1993).

Individual Risk Factors Proposed in the ITMSV. More than 20 individual risk factors are proposed in the ITMSV (see Figure 1). How these risk factors are integrated to cause stalking violence varies across individuals, circumstances, and the severity of violence. It is acknowledged that behavior is complex and there are many different pathways to violence. Therefore, there is scope for many and varied interactions between risk factors. However, regardless of complex and varied interactions: 
RUNNING HEAD: Are different risk factors associated with moderate and severe stalking violence?

(a) Severely violent stalkers should be characterized by a greater number and more severe types of predisposing factors than moderately violent stalkers (e.g., violent family and friends, sociocultural beliefs supportive of violence, narcissism, borderline personality features, a need for control, and a history of severe violence). Moderately violent stalkers should be characterized by few and less severe predisposing factors (e.g., a history of moderate violence and domestic violence).

(b) Contextual factors should increase the likelihood of any violence occurring, whether it is moderate or severe in nature. Therefore, intentions, triggering events, opportunities, and disinhibitors should be associated with both moderate and severe stalking violence.

(c) Combining risk factors (i.e., main effects) should improve assessments of risk, particularly when predisposing and contextual factors are combined, with more risk factors associated with higher risks of violence.

These simple propositions, based on the independent relationship between risk factors from the ITMSV and stalking violence, are valuable for risk assessment practice since (a) violence risk assessments typically evaluate risk according to the accumulation of individual risk factors, based on their independent association with violence rather than interactions (see Putnins, 2005, Thompson \& Stewart, 2011) and (b) understanding the pertinence of individual variables is necessary given that decisions may need to be made based on a few available risk factors and contextual factors are subject to change. Consequently, even without assessing interactions, there is still much to be learned from individual risk factors and the accumulation of these factors. These more simple propositions, rather than complex interactions, will be examined in this research.

Sex. One challenge to the application of theoretical models of interpersonal violence to stalking violence relates to the issue of sex. Most theoretical frameworks for interpersonal violence are developed and empirically tested on males and male perpetrators (e.g., Marshall \& Barbaree, 1990; McKenry et al., 1995; White, Kowlaski, Lyndon, \& Valentine, 2000), 
including many of those utilized in the ITMSV. However, in the context of stalking violence, there is some evidence that males and females may perpetrate, and be victimized, at comparable rates (see Rosenfeld \& Harmon, 2002; Sheridan \& Roberts, 2011; Sinclair \& Frieze, 2000; Thompson, Dennison, \& Stewart, 2012). If females perpetrate comparable rates of stalking violence, it is difficult to determine whether models largely developed and empirically tested on male perpetrators will be applicable to female stalkers. The ITMSV is intended to be applied to both male and female stalkers. However, it is unknown whether all the theories included in this model are applicable to females. Consequently, this will be investigated in this paper.

\section{The Current Study}

Although the risk factors from the ITMSV are derived from existing theories and research, most of these factors have not been examined in the context of stalking violence (e.g., violent families of origin, violent friends, violent relational entitlement, need for control, the severity of stalkers' history of violence, and triggering events). Furthermore, those factors that have been examined have inconsistent findings and/or have rarely been examined across the severity of stalking violence (e.g., revenge motives, threats, history of violence) or as noncomposite variables (e.g., narcissism, borderline personality features).

This study aims to explore the value of individual risk factors proposed in the ITMSV by (a) investigating the independent effect of many of these risk factors across no violence, moderate violence, and severe violence and (b) exploring which combination of risk factors best predicts moderate and severe stalking violence. In doing so, risk factors with inconsistent evidence in the current literature will be re-investigated across no, moderate, and severe violence. Additionally, new risk factors proposed by the theoretical model will be examined. Although Thompson's (2009) model specifies the theoretical mechanisms that account for how risk factors exert their influence and proposes complex interactions between these factors, 
RUNNING HEAD: Are different risk factors associated with moderate and severe stalking violence?

this study aims to investigate whether these factors are independently associated with moderate and/or severe stalking violence as a precursor to comprehensive examinations of the mechanisms that underpin such associations and related interactions.

The present study examines self-reported stalking violence perpetration in a convenience sample of relational stalkers from Queensland, Australia. Risk factors will be investigated in the context of stalking that occurs after the dissolution of an intimate relationship or in the pursuit of an intimate relationship. This context was selected as (a) certain factors from the ITMSV are arguably more relevant to, or exacerbated by, a relational context (e.g., violent relational entitlement, a need for control, and history of domestic violence); (b) much stalking occurs in the context of relationship breakdowns or relationship pursuits (Purcell, Pathe, \& Mullen, 2002; Tjaden, Thoennes, \& Allison, 2000); and (c) research suggests that stalking violence is most likely to occur in the context of ex-intimate stalking (e.g., Rosenfeld, 2004).

Three overarching research questions will be investigated:

(1) Are individual predisposing risk factors (including adult attachment type, need for control, narcissism, borderline personality features, violent relational entitlement, violent family of origin, violent friends, police contact, history of moderate domestic violence, history of moderate violence, history of any severe violence) proposed in the ITMSV independently associated with (a) moderate stalking violence and (b) severe stalking violence? Biological propensity and opportunities are omitted as they could not be reliably examined through a questionnaire.

(2) Are individual contextual risk factors (including threats, revenge motive, triggering events, alcohol use, illegal drug use, anger, jealousy, ex-intimate relationship) proposed in the ITMSV independently associated with (a) moderate stalking violence and (b) severe stalking violence? 
RUNNING HEAD: Are different risk factors associated with moderate and severe stalking violence?

(3) What combination of risk factors from the ITMSV best predicts moderate and severe stalking violence?

\section{Method}

\section{Participants}

A convenience sample of 1738 participants from South-East Queensland, Australia participated in this research $(24.4 \%$ male, $70.2 \%$ female, missing data $=5.4 \%)$. However, only participants classified as relational stalkers $(N=703,40.4 \%)$ were included in the present study (20.9\% male, $73.1 \%$ female, $6.0 \%$ missing data). Although female participants were more likely to be classified as relational stalkers $(n=514,42.1 \%$ of all 1220 female participants) than male participants ( $n=147,34.7 \%$ of all 424 male participants), $\chi^{2}(1, N$ $=1644)=7.27, p=.007, \phi \square=.067$, the strength of this association was weak. The ages of relational stalkers ranged from 17 to 62 years $(M=23.5$ years, $M d n=21$ years, $S D=8.5$, missing $n=44)$. Relational stalkers were typically single (34\%), in a dating relationship (26\%) or married/defacto (28\%), with only $6 \%$ divorced/separated/widowed (missing data $=6.0 \%$ ). Only $4 \%$ of relational stalkers had not completed High School, 39\% had completed High School, and 51\% had tertiary qualifications (missing data $=6.0 \%$ ). Participants were treated in accordance with the ethical principles of the National Health and Medical Research Council.

\section{Materials}

A self-report perpetration questionnaire was utilized to measure (a) relational stalking (b) stalking violence, and (c) 20 predisposing and contextual risk factors from the ITMSV. The questionnaire was available in two formats; a web-based format ( $n=610 ; 86.8 \%)$ and a paper-based format ( $n=93 ; 13.2 \%)$. Consistent with previous research (e.g., Knapp \& Kirk 2003), no independent or dependent variables differed across questionnaire format.

Relational stalking. To measure relational stalking behavior, participants were asked to report whether they had ever perpetrated any of 25 behaviors that they knew were unwanted after they had broken up with an intimate partner or had been rejected by someone they 
wanted an intimate relationship with (Cronbach's alpha $=.8$ ). The list of stalking behaviors primarily comprised items from Spitzberg and Cupach’s (1997) Relational Pursuit - Pursuer Short Form (Version 2). Minor changes were made to the scale to ensure that the behaviors were consistent with the behaviors typically used in stalking legislation and research (e.g., Davis, Ace, \& Andra, 2000; Purcell, Pathe, \& Mullen, 2000; Sheridan, Davies, \& Boon, 2001); including combining similar items, excluding some items (e.g., making exaggerated expressions of affection), and including some additional behaviors (e.g., unwanted telephone calls; full scale items are available in Thompson, 2009). Participants who had perpetrated stalking-like behaviors towards multiple people were required to select one person who "had the biggest impact on them" and complete the checklist again for this person only. This ensured that the data pertained to relational stalking perpetrated against one person, rather than an accumulation of stalking-like behaviors perpetrated against multiple people. The behaviors were not required to induce victim fear as perpetrators tend to have little insight into the effect of their intrusions on the victim (Davis et al., 2000; Langhinrichsen-Rohling, Palarea, Cohen, \& Rohling, 2000; Sinclair \& Frieze, 2005). Consequently, their accounts of victim fear may be unreliable and unnecessarily restrictive on sample size. Therefore, while research using stalking victims typically requires participants to experience fear to differentiate harassment from stalking (e.g., Baum, Catalano, Rand, \& Rose, 2009), victim fear could not be used for this purpose in this study.

In this research, participants were classified as relational stalkers if they had perpetrated five or more intrusions from the relational stalking checklist against any one person. Here, the number of intrusions was calculated by adding the frequency of each stalking behavior (e.g., three behaviors performed five times resulted in a score of 15 intrusions). The decision to use this threshold was informed by Thompson and Dennison's (2008) research that investigated the impact of different behavioral thresholds on sample size and the severity of stalking-like behavior in a sample of unconvicted perpetrators (i.e., cut- 
points of two, five and ten or more intrusions). According to this research, although stalking legislation generally utilizes a threshold of two or more behaviors (see Dennison, 2007; Ogilvie, 2000), this threshold was judged to be too encompassing when victim fear could not be reliably assessed, as is the case in self-report perpetration questionnaires (i.e., perpetrated by two thirds of Thompson \& Dennison's sample). A more stringent threshold of ten or more intrusions resulted in a more restrictive sample (i.e., 22.4\%), however, a lot of violent and threatening behavior was excluded that could have induced fear. Moreover, this threshold significantly exceeds legislated thresholds. A threshold of five or more intrusions was judged to balance these issues. This threshold was more stringent than a threshold of two, classifying 40\% less participants as stalkers and therefore limiting relatively common behavioral patterns. At the same time, 50\% more violent participants and 50\% more threatening participants were identified than a threshold of ten. Consequently a threshold of five may reduce the loss of participants who are threatening and/or violent (and who may have induced fear when victim's fear cannot be directly assessed) but did not perpetrate ten or more intrusions. Therefore, relational stalking is operationally defined in the present research as five or more unwanted intrusions perpetrated against any one person after the breakdown of an intimate relationship, or in the pursuit of an intimate relationship. This operational definition has been used in previous stalking research (see Thompson et al., 2012).

Although the definition used for stalking in this study was devised from careful consideration of definitional issues, it is improbable that all participants classified as relational stalkers could be convicted under anti-stalking legislation. This is due to the complexities associated with simulating legislative criteria in operational definitions of stalking for unconvicted perpetrators. Nevertheless, for simplicity, these participants will be referred to as relational stalkers. Since partner stalking is often regarded to be a form of intimate partner violence (IPV; Melton, 2007; Norris, Huss, \& Palarea, 2011), there may be overlaps between 
some of the relational stalking in this study and IPV. Moreover, in some cases the relational stalking may be an extension of IPV that occurred during the relationship.

Stalking violence. To measure stalking violence, participants who perpetrated relational stalking behaviors were asked whether they had ever attempted to, or actually did, any of 23 physically violent acts to the person to whom the unwanted behaviors were targeted towards, or towards someone for whom this person cared, during the course of stalking. The list of violent acts primarily comprised items from two subscales from the psychometrically sound CTS2 (physical assault and sexual coercion subscales; Straus et al., 1996). Additional violent behaviors commonly reported in stalking research were also incorporated in the checklist (full items are available in Thompson, 2009). Participants also reported other physically violent behaviors they perpetrated that were excluded from the checklist (e.g., headbutting). Violence was classified as either moderate or severe violence according to the CTS2 and the probable severity of the consequences of the behavior (Cronbach's alpha $=.8$ for moderate violence and .7 for severe violence). Participants were classified into three mutually exclusive categories according to the most severe form of violence they perpetrated; 'not violent', 'moderately violent' or 'severely violent'. Participants who indicated that they engaged in violence as a means of self defense only were not classified as violent $(n=19$; $7.1 \%)$.

\section{Risk factors}

A series of questions were used to assess predisposing and contextual risk factors from the ITMSV. To ensure risk factors preceded violence, participants were asked to report on the presence or absence of these factors prior to the stalking violence. This was not always possible for predisposing risk factors, such as attachment and personality disorders. However, these risk factors are arguably stable over time.

\section{Predisposing risk factors.}


Sociocultural risk factors. Three sociocultural risk factors were assessed: violent family of origin, violent friends, and violent relational entitlement. Violent family of origin was coded present (versus absent) if participants responded yes to any of these questions: 'did you ever see or hear your parents or step-parents do any of the following things: use a knife or gun, punch or hit with something that could hurt, choke, slam against a wall, beat up, burn or scald or kick? To one another? To a sibling? To you?' (items derived from the serious physical assault scale of the CTS2). Violent friends was coded present (versus absent) if participants reported that one or more of their friends 'were often in physical fights or punch-ups' (question adapted from Benda \& Toombs, 2002; Prinstein, Boergers, \& Spirito, 2001).

Violent relational entitlement was measured using Mazerolle’s (1999) Intimate Partner Violence Justification Scale (Cronbach's alpha co-efficient $=.8$ ). The scale assessed participants' agreement with justifications for using violence against an intimate partner, for example "it is okay for a man to hit or slap his partner if his partner stays out past midnight without telling him where he/she is” (scored agree/disagree). Although the original scale was designed to assess violence perpetrated by men against women, given the high representation of women participants predicted for the sample the scale was presented twice to assess justifications for male- and female-perpetrated intimate partner violence (total = 18 items). Scores from both scales were combined to measure general violent relational entitlement. Due to a floor effect (i.e., $46.8 \%$ of relational stalkers did not endorse any items and $75 \%$ endorsed two or less items), violent relational entitlement was coded dichotomously (no support/one or more justification). Other cut-points trialed did not improve the predictive accuracy of this risk factor.

Psychological risk factors. Four psychological risk factors were assessed: adult attachment style, need for control, narcissism, and borderline personality features. Adult attachment style was measured using Brennan, Clark, and Shaver’s (1998) widely used and psychometrically sound Experiences in Close Relationships Questionnaire (36 items; 
RUNNING HEAD: Are different risk factors associated with moderate and severe stalking violence?

Cronbach’s alpha $=.9$ ). Examples of items included in the scale are "I worry about being abandoned" and "I prefer not to show a partner how I feel deep down". Participants were classified into the following attachment styles using the computational guidelines provided by Brennan and colleagues: secure, fearful, preoccupied, and dismissing. Need for control was measured using Follingstad and associates’ (1999) psychometrically sound Control Scale Short Form (25 items; Cronbach’s alpha $=.9$ ). This scale has been used to measure need for control in previous stalking and domestic violence research (e.g., Davis et al., 2000; Follingstad et al., 1999). This scale assesses participants' engagement in controlling behaviors in their recent relationships, defined as within the previous 6 months. An example item is "how often have you tried to insist that you are the one to decide whom you and your dating partner spend time with?”. Due to a positively skewed distribution (possible score range = 25 to $100 ; M=36.08, M d n=35, S D=8.74$ ), need for control scores were dichotomized into scores above and below the median. Alternative cut-points trialed did not improve the predictive accuracy of this risk factor. Participants who had not been in relationships in the previous 6 months did not complete this checklist.

Narcissism and borderline personality features were assessed using Hyler’s (1994) extensively used Personality Diagnostic Questionnaire-Version 4 (PDQ-4). The complete scale consists of 100 items assessing personality diagnoses based on DSM-IV criteria. Nine items measuring borderline personality traits (BPDT; Cronbach's alpha $=.7$ ) and nine items measuring narcissistic personality traits (NPDT; Cronbach's alpha $=.6$; this coefficient is comparable to those attained in previous research e.g., Samuel \& Widiger, 2008) were utilized. An example of a question included in the borderline personality subscale is "I'll go to extremes to prevent those who I love from ever leaving me”. An example of a question included in the narcissistic personality subscale is "I very much need other people to take notice of me or compliment me”. Participants were classified as having BPDT (versus not) or NPDT (versus not) according to the computational guidelines provided by Hyler. 
Historical risk factors. Four historical risk factors were assessed: a history of moderate violence, a history of moderate domestic violence, a history of any severe violence, and previous police contact. A history of moderate violence and a history of moderate domestic violence were coded present (versus absent) if participants engaged in any of five behaviors from the minor physical assault scale of the CTS2 towards a non-intimate partner or an intimate partner, respectively, prior to the stalking-like behavior (including slapping, pushing or shoving, grabbing, twisting someone's arm or hair, throwing something at someone that could hurt). History of severe violence and domestic violence was coded present (versus absent) if participants engaged in any of seven behaviors from the serious physical assault scale (including using a knife or gun, punching or hitting with something that could hurt, choking, slamming against a wall, beating up, burning or scalding, kicking) and/or three items selected from the sexual coercion scale of the CTS2 (including used force [hitting, holding down, weapon] to make someone have sex, oral sex or anal sex, used threats to make someone have sex, oral sex or anal sex or forced any sexual contact) towards a non-intimate partner or an intimate partner prior to the stalking-like behaviors. Intimate and non-intimate severe violence were combined into one risk factor due to the low endorsement of these items. Police contact was measured by asking participants if they had "ever been in trouble with the police prior to the (stalking-like) behavior” (scored Yes/No).

\section{Contextual risk factors.}

Triggering events. Triggering events was coded present (versus absent) if participants indicated that their intrusive behavior was triggered by any one of the following events: 'You were in an argument', 'He or she confronted you' and 'You were in a dispute or in conflict with him or her'. Protection orders was measured as a separate triggering event. Protection orders was coded present (versus absent) if participants indicated that the target or his/her family or friends had sought a protection or restraining order or a domestic violence order. 
Intentions. Two risk factors indicative of intentions were assessed: revenge motives and threats. To assess revenge motives, participants were asked why they engaged in the intrusive behaviors and were provided with 31 responses from which they could select multiple responses (two responses measured revenge motives). Revenge motives was coded present (versus absent) if participants selected any of these responses: 'To get them back for what they did to you' and 'You wanted to get revenge'. Threats were coded present (versus absent) if the participant had ever threatened to (1) harm to the target (2) harm someone the stalking target cared about, (3) kill the target or (4) kill someone the stalking target cared about.

Disinhibitors. Four disinhibitors were assessed: anger, jealousy, illegal drug use, and alcohol use. Anger and jealousy were assessed by asking participants 'How did you feel when you were behaving this way?' and were provided with 21 feelings from which they could select multiple responses. Anger was coded present (versus absent) if any one of three responses were selected: vengeful, angry, and rage (inter-item correlations $=.3$ to .4). Jealousy was coded present (versus absent) if one response was selected; jealous. Alcohol and illicit drug use were assessed by asking participants whether they had "used alcohol (scored always/sometimes/never) or illegal drugs (scored always/sometimes/never) while they engaged in the stalking-like behavior”. If respondents reported that they had used either of these substances (i.e., always or sometimes), the relevant substance was coded present (versus absent).

\section{Procedure}

Participants were recruited through seven sampling techniques: (1) 800 brochures advertising the web-based questionnaire were distributed in areas frequented by large numbers of people, including South-East Queensland's CBD mall, three inner-city train stations, and two busy South-East Queensland CBD footpaths; (2) 600 letterbox drops were distributed advertising the web-based questionnaire in four randomly selected South-East Queensland 
RUNNING HEAD: Are different risk factors associated with moderate and severe stalking violence?

suburbs; (3) an e-mail was distributed to members of the 'Crimnet' mailing list, comprising a network of academics, professionals, practitioners, and students in the criminal justice field; (4) a Griffith University-wide email was distributed to staff and students; (5) an advertisement was placed on the Griffith University computer laboratory homepage; (6) the study was included in research participation schemes in three undergraduate criminology courses; and (7) the researcher attended five undergraduate lectures to invite student participation. Approximately $40 \%$ of the total sample were obtained from the Griffith University staff and student community ( $n=712 ; 41 \%$ ). Both general community members and students were recruited through the University recruitment methods and both general community members and students were recruited through the community recruitment methods. Participants were informed that the purpose of the study was to investigate the behaviors utilized by individuals after breaking up from an intimate relationship or during the pursuit of a new intimate relationship. The behavior was not labeled 'stalking' to circumvent error that may arise from individuals' preconceived notions of what constitutes stalking. Although the procedure was intended to identify a somewhat representative sample of the community, the disproportionate numbers of female participants and highly educated participants may have arisen because (a) higher educated people may be more willing to self-select to participate in research (b) higher educated people are likely to be obtained from a sample of university staff and students, and (c) females may be more willing to participate in relationship research. These issues potentially limit the generalizability of this research to males and less educated people.

\section{Analysis}

Results were analyzed using SPSS for Windows, Version 14.0. Prior to conducting analyses, data were examined to ensure statistical assumptions were not violated. Unless noted, all necessary assumptions were met. The postdictive validity of each individual risk factor was examined using chi-square analyses. For those risk factors with significant chisquare statistics, cells with adjusted residuals exceeding absolute 2.0 were deemed to 
RUNNING HEAD: Are different risk factors associated with moderate and severe stalking violence?

significantly differ (Cooksey, 2007). Although multiple analyses were conducted, Bonferroni’s adjustment was not used because (a) Bonferroni’s adjustment has been criticized as overly conservative (Jaccard \& Wan, 1996), especially when large numbers of variables are examined; (b) when the $p$ values were added across all significant values, the total still fell below .05 (i.e., .038) and therefore Type I error rates were not inflated (Tabachnick \& Fidell, 2001); and (c) due to the exploratory nature of this study, the researchers believed it was premature to exclude the importance of risk factors due to an overly conservative $p$ value. To examine which combination of risk factors best predicted stalking violence, logistic regressions were conducted.

\section{Results}

The results will be reported in five sections. In the first two sections, the nature of stalking and violence in the sample will be discussed to provide a context for addressing the research questions. In the last three sections, the relationship between risk factors and violence will be reported according to the three research questions proposed for this study.

\section{The Nature of Stalking Perpetration in the Sample}

The majority of participants classified as relational stalkers ( $n=608$; 86.5\%) perpetrated more than five intrusions (i.e., the minimum threshold used to define stalking in this study). The average number of intrusions perpetrated was 15.7 ( $M d n=10 ; S D=14.6$; range $=5-118)$. Most relational stalkers persisted for longer than one month $(n=422 ; 60.1 \%)$ and $17.8 \%$ persisted for longer than 6 months $(n=125)$. Most relational stalking was perpetrated against a target of the opposite sex ( $n=620,88.2 \%$; missing $n=42,6.0 \%)$ and occurred after the dissolution of an intimate relationship ( $n=638 ; 90.8 \%)$ rather than during the pursuit of an intimate relationship ( $n=65,9.2 \%)$. The vast majority of relational stalkers reported neither police involvement nor the issuance of a restraining order or a domestic violence order ( $n=690,98.2 \%$ ), with only eight respondents issued protection orders. Due to 
RUNNING HEAD: Are different risk factors associated with moderate and severe stalking violence?

the infrequency of protection orders and the small number of pursuit stalkers, these variables were not further examined.

\section{Stalking Violence Perpetration}

Just over $40 \%$ of relational stalkers $(n=293)$ reported the actual or attempted perpetration of stalking violence. The mean number of violent acts was $5.7(M d n=3$; $S D=$ 8.1; range=1-60). Almost two thirds of the violence perpetrated in the sample was moderate violence perpetrated in the absence of severe violence $(n=184 ; 62.8 \%)$. Over a third of violence perpetrated was severe $(n=109 ; 37.2 \%)$, most of which was perpetrated in conjunction with moderate violence $(n=98 ; 89.9 \%)$. Violence was primarily perpetrated against the stalking target (90\%). Just $10 \%$ of violent acts were perpetrated against someone the stalking target cared about and less than $1 \%$ was perpetrated against their pet. Due to the infrequency of violence perpetrated against third parties and pets, subsequent analyses will not distinguish between victims of violence.

Although stalking violence did not differ according to participants' age, $\chi^{2}(2, N=$ $703)=0.48, p=.79$, Nagelkerke $\mathrm{R} 2=0.001$, or highest educational qualification, $\chi^{2}(4, N$ $=694)=1.22, p=.876$, Cramer's $V=.04$, stalking violence varied significantly across sex, $\chi^{2}$ (2, $N=661)=10.61, p=.005$, Cramer's $V=.13$. Females perpetrated moderate violence (29\%) at significantly higher rates than their male counterparts (17\%; adjusted residuals \pm 2.9); however, males and females perpetrated severe violence at comparable rates $(14.3 \%$ and $16.5 \%$ respectively; adjusted residuals \pm 0.7 ). Subsequent analyses are not disaggregated across sex as data screening indicated that controlling for sex did not alter the findings.

\section{Research Question 1: Predisposing Risk Factors}

Sociocultural factors. Three sociocultural factors from the ITMSV were investigated: violent family of origin, violent friends, and violent relational entitlement (see Table 2). All of these factors were significantly associated with stalking violence; violent family of origin, $\chi^{2}$ $(2, N=670)=8.89, p=.012$, Cramer's $V=.12$, violent friends, $\chi 2(2, N=673)=13.51, p=$ 
RUNNING HEAD: Are different risk factors associated with moderate and severe stalking violence?

.001 , Cramer's $V=.14$, and violent relational entitlement, $\chi 2(2, N=703)=13.24, p<.001$, Cramer's $V=.14$. Inspection of the adjusted residuals indicated that all three sociocultural factors were associated with severe stalking violence (violent family of origin adjusted residuals $= \pm 2.9$; violent friends adjusted residuals $= \pm 3.6$; violent relational entitlement adjusted residuals $= \pm 3.3$ ). However, none of these factors were associated with moderate stalking violence (violent family of origin adjusted residuals $= \pm 0.2$; violent friends adjusted residuals $= \pm 0.5$; violent relational entitlement adjusted residuals $= \pm 0.5$ ).

\section{TABLE 2 ABOUT HERE}

Psychological factors. Four psychological factors from the ITMSV were investigated: adult attachment types, need for control, narcissism, and borderline personality traits (see Table 2). Three of these factors were significantly associated with stalking violence; need for control, $\chi 2(2, N=514)=15.57, p<.001$, Cramer's $V=.17$, narcissism, $\chi 2(2, N=703)=$ 10.36, $p=.006$, Cramer's $V=.12$, and borderline personality traits, $\chi 2(2, N=703)=18.22, p$ $<.001$, Cramer's $V=.16$. Inspection of the adjusted residuals indicated that all three psychological factors were associated with severe stalking violence (need for control adjusted residuals $= \pm 3.9$; narcissism adjusted residuals $= \pm 3.1$; borderline personality traits adjusted residuals $= \pm 3.4$ ). However, none of these factors were associated with moderate stalking violence (need for control adjusted residuals $= \pm 0.9$; narcissism adjusted residuals $= \pm 0.1$; borderline personality traits adjusted residuals $= \pm 1.6$ ). Adult attachment types were not significantly associated with stalking violence, $\chi 2(6, N=703)=11.01, p=.09$. Cramer's $V=$ .09 .

Historical factors. Four historical factors from the ITMSV were investigated: a history of moderate violence, a history of moderate domestic violence, a history of any severe violence, and previous police contact (see Table 2). As only 5\% of relational stalkers indicated that they 'had previously been in trouble with the police', previous police contact was not investigated using inferential statistics (see Tabachnick \& Fidell, 2001). The remaining three 
RUNNING HEAD: Are different risk factors associated with moderate and severe stalking violence?

historical factors were significantly associated with stalking violence; history of moderate violence, $\chi 2(2, N=703)=39.67, p<.001$, Cramer's $V=.24$, history of moderate domestic violence, $\chi^{2}(2, N=703)=84.98, p<.001$, Cramer's $V=.35$, and history of any severe violence, $\chi^{2}(2, N=703)=41.27, p<.001$, Cramer's $V=.24$. Inspection of the adjusted residuals indicated that all three historical factors were associated with severe stalking violence (history of moderate violence $= \pm 4$. 7 ; history of moderate domestic violence $= \pm 6.5$; history of any severe violence adjusted residuals $= \pm 6.4$ ). While a history of moderate violence and history of moderate domestic violence were associated with moderate stalking violence (adjusted residuals $= \pm 2.9$ and \pm 4.7 , respectively), a history of any severe violence was not (adjusted residuals $= \pm 1.9$ ).

\section{Research Question 2: Contextual Risk Factors}

Triggering events. Triggering events were significantly associated with stalking violence; $\chi^{2}(2, N=703)=77.79, p<.001$, Cramer's $V=.33$ (see Table 3). Inspection of the adjusted residuals indicated that triggering events were associated with severe stalking violence (adjusted residuals $= \pm 6.1$ ) as well as moderate stalking violence (adjusted residuals $= \pm 4.6)$.

\section{TABLE 3 ABOUT HERE}

Intentions. Two risk factors indicative of intentions were investigated: revenge motives and threats (see Table 3). Both of these factors were significantly associated with stalking violence; revenge motives, $\chi 2(2, N=703)=41.59, p<.001$, Cramer's $V=.24$, and threats, $\chi 2(2, N=703)=89.95, p<.001$, Cramer's $V=.36$. Inspection of the adjusted residuals indicated that revenge motives was associated with both severe stalking violence (adjusted residuals $= \pm 5.3$ ) and moderate stalking violence (adjusted residuals $= \pm 2.3$ ). While threats were associated with severe stalking violence (adjusted residuals $= \pm 8.8$ ), they were not associated with moderate stalking violence (adjusted residuals $= \pm 1.1$ ). 
Disinhibitors. Four disinhibitors from the ITMSV were investigated: anger, jealousy, illicit drug use, and alcohol use (see Table 3). Three of these factors were significantly associated with stalking violence; anger, $\chi 2(2, N=703)=81.05, p<.001$, Cramer's $V=.34$, illicit drug use, $\chi^{2}(2, N=703)=32.09, p<.001$, Cramer's $V=.21$, and alcohol use, $\chi^{2}(2, N$ $=703)=10.54, p=.005$, Cramer's $V=.12$. Inspection of the adjusted residuals indicated that all three disinhibitors were associated with severe stalking violence (anger $= \pm 6.9$; illicit drug use $= \pm 5.6$; alcohol use $= \pm 2.5$ ). However, only anger was associated with moderate stalking violence (anger $= \pm 3.9$; illicit drug use $= \pm 0.5$; alcohol use $= \pm 1.4$ ). Jealousy was not significantly associated with stalking violence, $\chi 2(2, N=703)=5.31, p=.070$, Cramer's $V=$ .09 .

\section{Research Question 3: Combining risk factors from the ITMSV}

As different risk factors were significant for moderate and severe violence at the bivariate level, moderate and severe violence were analyzed in separate binary logistic regressions. Prior to conducting these analyses, correlations were computed between all significant predictors. While many predictors were significantly correlated, no correlations were high enough to warrant their exclusion or combination (maximum $r=.37$ ).

Multivariate model for moderate violence versus no violence. A sequential logistic regression was conducted to examine which combination of risk factors significant at the bivariate level (i.e., history of moderate domestic violence, history of moderate violence, revenge motives, triggering events, and anger) best predicted moderate stalking violence. As sex was significantly associated with moderate violence, sex was entered in the first block as a covariate. The sex-only model was a significant improvement over the constant-only model $\left(\chi^{2}\right.$ [1, $N=555]=10.67, p=.001$ ), although sex alone accounted for a small proportion of variance, Nagelkerke $R^{2}=.03$. When the five predictors were entered into the model, there was a significant improvement over the sex-only model $\left(\chi^{2}[5, N=555]=97.88, p<.001\right)$; entire model, $\chi^{2}(6, N=555)=108.55, p<.001$, Nagelkerke $R^{2}=0.25$. A ROC analysis using 
RUNNING HEAD: Are different risk factors associated with moderate and severe stalking violence?

the predicted probabilities from the logistic regression indicated that classification accuracy of the model was moderate-to-strong $($ ROC AUC $=.76, C I=.72-.80, p<.001)$. Wald statistics indicated that a history of moderate domestic violence, anger, and triggering events significantly differentiated moderately violent stalkers from non-violent stalkers over and above the remainder of the set of predictors (see Table 4).

\section{TABLE 4 ABOUT HERE}

Multivariate model for severe violence versus no violence. Due to the large number of risk factors significantly associated with severe violence at the bivariate level, separate logistic regressions were conducted for predisposing and contextual risk factors. The strongest predictors from each model were then entered into a final logistic regression (see Tabachnick \& Fidell, 2001 and Rosenfeld \& Harmon, 2002).

Logistic regression with predisposing risk factors. The predisposing risk factors significantly associated with severe violence at the bivariate level were entered into a direct logistic regression analysis (i.e., need for control, violent relational entitlement, narcissism, borderline personality features, violent family of origin, violent friends, history of moderate domestic violence, history of moderate violence, and history of any severe violence). Due to high rates of missing data on need for control, logistic regressions were run with and without need for control. The model that includes need for control will be reported because (a) when need for control was included, it significantly contributed to the model and (b) the inclusion of this variable did not impact the significance of the other variables or the strength of the model. The results indicated that the set of nine predictors were a significant improvement over the constant-only model, $\chi^{2}(9, N=383)=83.69, p<.001$, Nagelkerke $\mathrm{R}^{2}=.30$ (for the model excluding need for control were, $\chi^{2}[8, N=495]=99.98, p<.001$, Nagelkerke $\mathrm{R}^{2}=.28$ ). Wald statistics indicated that a need for control, violent relational entitlement, history of moderate domestic violence, and history of any severe violence were significant at differentiating 
RUNNING HEAD: Are different risk factors associated with moderate and severe stalking violence?

severely violent stalkers from non-violent stalkers over and above the remainder of the set of predictors (see Table 5).

\section{TABLE 5 ABOUT HERE}

Logistic regression with contextual factors. Contextual factors significantly associated with severe violence at the bivariate level were entered into a direct logistic regression analysis (i.e., threats, revenge motives, triggering events, alcohol use, illicit drug use, and anger). Together, the set of six predictors were a significant improvement over the constantonly model, $\chi^{2}(6, N=519)=151.43, p<.001$, Nagelkerke $\mathrm{R}^{2}=.39$. Wald statistics indicated that threats, triggering events, illicit drug use, and anger were significant at differentiating severely violent stalkers from non-violent stalkers over and above the remainder of the set of predictors (see Table 5).

The integrated model. Risk factors that significantly contributed to the prediction of severe violence in the predisposing and contextual models were entered into a final direct logistic regression, reflecting the strongest group of predictors (i.e., need for control, violent relational entitlement, history of moderate domestic violence, history of any severe violence, threats, triggering events, illicit drug use, and anger). Again, analyses were run both with and without need for control. When need for control was excluded, the set of seven predictors were a significant improvement over the constant-only model, $\chi^{2}(7, N=519)=194.36, p<.001$, Nagelkerke $\mathrm{R}^{2}=.49$. Wald statistics indicated that a history of moderate domestic violence, a history of severe violence, threats, triggering events, illicit drug use, and anger significantly differentiated severely violent stalkers from non-violent stalkers over and above the remainder of the set of predictors (see Table 5). The model that included need for control was also a significant improvement over the constant-only model, $\chi^{2}(8, N=383)=147.61, p<.001$, Nagelkerke $\mathrm{R}^{2}=.49$. The same individual variables were significant in this model with two exceptions (1) need for control was significant and (2) drug use was no longer significant (see 
RUNNING HEAD: Are different risk factors associated with moderate and severe stalking violence?

Table 5). Inspection of the data revealed that need for control and drug use were not significantly correlated and that missing values on need for control were not significantly associated with severe violence or drug use. ROC AUCs using the predicted probabilities from the models with $(R O C A U C=.88, C I=.84-.92, p<.001)$ and without need for control $(R O C$ AUC $=.88, C I=.85-.92, p<.001$ ) were both strong and did not significantly differ. Therefore, either model could be used.

\section{Discussion}

This study investigated the relationship between risk factors proposed in the ITMSV and stalking violence in a convenience sample of relational stalkers in Queensland, Australia. Several risk factors examined in previous stalking violence research were analyzed across the severity of violence as well as additional variables proposed in the model. With the exception of adult attachment types and jealousy, all predisposing and contextual risk factors were associated with severe violence at the bivariate level. Fewer risk factors were significantly associated with moderate stalking violence at the bivariate level, particularly in relation to predisposing factors. Multivariate models indicated that combining predisposing and contextual factors resulted in strong predictions of both moderate and severe violence. Moderate stalking violence was predicted with moderate-to-strong accuracy by combining a history of moderate domestic violence, triggering events, and anger. Severe stalking violence was predicted with strong accuracy with the same combination of variables in addition to a history of severe violence, need for control, threats, and illicit drug use.

\section{Risk Factors Independently Associated with Moderate and Severe Stalking Violence}

Eighteen of the 20 risk factors examined in this research were independently associated with moderate and/or severe stalking violence at the bivariate level. Although not all of these risk factors were retained in multivariate models, it is premature to disregard the importance of risk factors statistically significant at the bivariate level as the multivariate analyses did not investigate interactions and potential mediating and moderating effects. Therefore, the 
RUNNING HEAD: Are different risk factors associated with moderate and severe stalking violence?

bivariate findings will be discussed in this section. The authors acknowledge that risk factors are likely to interact; however, an analysis of complex and varied interactions proposed by the model was beyond the scope of this research. Additionally, as stated earlier, understanding the independent relationship of individual risk factors has value for stalking violence risk assessments. The multivariate findings will be discussed in a subsequent section in relation to combining risk factors.

Predisposing factors. There was support for the utility of nine of the ten predisposing risk factors examined. However, the importance of these risk factors differed markedly across moderate and severe stalking violence. While both sociocultural (i.e., violent families of origin, violent friends, and violent relational entitlement) and psychological (i.e., need for control, narcissism, borderline personality features) predispositions were associated with severe violence, neither of these types of predisposing risk factors were associated with moderate violence. Additionally, although severe stalking violence was associated with a history of severe violence, moderate stalking violence was not. The only predisposing factors associated with moderate violence were moderate in nature (i.e., a history of moderate violence and a history of moderate domestic violence). Therefore, consistent with the ITMSV, fewer and less severe types of predisposing risk factors were associated with moderate stalking violence. Additionally, a greater number and more severe types of predisposing factors were associated with severe violence. These findings support the utility of a range of predisposing risk factors previously unexamined for stalking violence, including violent families of origin, violent friends, violent relational entitlement, need for control, narcissism, borderline personality features, and the severity of stalkers' history of violence. These findings also demonstrate the value of disaggregating two composite variables from previous stalking violence research, personality disorders, and the severity of stalkers' histories of violence.

One predisposing risk factor derived from the ITMSV was not significantly associated with stalking violence; attachment types. Given the high rate of insecure attachments in this 
RUNNING HEAD: Are different risk factors associated with moderate and severe stalking violence?

study (i.e., 82\%) and previous stalking research (e.g., 85\%; Dutton \& Winstead, 2006), insecure attachments alone may have limited utility in differentiating violent and non-violent stalkers. Instead, as the current results suggest, specific characteristics associated with insecure attachments (e.g., a need for control) or extreme disorders of attachment (e.g., narcissistic or borderline personality traits) may be associated with stalking violence.

Contextual factors. Consistent with the ITMSV, there were risk factors across all three types of contextual factors associated with both moderate and severe stalking violence (i.e., intentions [revenge motives], triggering events, and disinhibitors [anger]). While anger and revenge have been examined in previous stalking violence research, this is the first time triggering events have been examined. Contrary to the ITMSV, three contextual factors were associated with severe stalking violence and not moderate stalking violence (i.e., alcohol use, illicit drug use, and threats). These findings require elaboration.

Although the ITMSV does not propose that the effects of substance use differ across moderate and severe violence, it is possible that severely violent stalkers are more likely to use alcohol and drugs in general or to have substance-related problems. Consistent with this, there is some evidence that a history of alcohol and/or drug abuse is associated with severe stalking violence but not moderate stalking violence (e.g., Brewster, 2003; Sheridan \& Roberts, 2011). Therefore, these findings may reflect these differences rather than the differential impact of disinhibitors. Alternatively, some research indicates that, for females, alcohol use may only be related to aggression in those already predisposed to violence (Giancola, 2002; Giancola, Saucher, \& Gussler-Burkhardt, 2003). Therefore, it is possible that the differential impact of predisposing risk factors across moderate and severe stalking violence may result in substance use further exacerbating the risk of severe stalking violence but not moderate stalking violence.

Although the ITMSV does not propose that the importance of threats varies across moderate and severe violence, given the rarity of threats in this study (i.e., $18 \%$ of relational 
RUNNING HEAD: Are different risk factors associated with moderate and severe stalking violence?

stalkers), those stalkers who threaten violence in non-legal samples may be relatively antisocial. Therefore, it may be that threats to harm or kill an individual are also associated with other predisposing variables and these characteristics predispose these individuals to both threaten violence as well as perpetrate violence. Although Sheridan and Roberts' (2011) research supported the importance of threats across the severity of violence in a non-legal victim sample, their study defined severe violence as that which caused injuries that resulted in medical treatment. Therefore, the definition of severe violence in the present study may have captured behaviors that would have only been classified as moderate violence in Sheridan and Roberts' study. Given the ambiguity around the findings for substance use and threats, additional research needs to determine whether these findings are related to interactions with predisposing variables rather than differences in the applicability of contextual factors. However, regardless of the origin of these differences, these findings provide further support for the importance of differentiating moderate and severe stalking violence.

One contextual risk factor derived from the ITMSV was not associated with either moderate or severe stalking violence; jealousy. It is possible that the non-significant finding for jealousy was due to the use of a single item to measure jealousy in this research. A standardized tool that measures jealousy may have rendered different results (e.g., the Communicative Responses to Jealousy Scale; Guerrero, Andersen, Jorgensen, Spitzberg, \& Eloy, 1995).

\section{What Combination of Risk Factors Best Predicts Moderate and Severe Violence?}

Multivariate analyses indicated that moderate stalking violence was best predicted by combining a history of moderate domestic violence, triggering events, and anger. Severe stalking violence was best predicted by the same combination of variables in addition to a history of any severe violence, need for control, threats, and illegal drug use. These models yielded strong predictions of both moderate (ROC AUC $=.76$ ) and severe violence (ROC AUC $=.88)$. In fact, the ROC AUCs for severe stalking violence are comparable to the highest 
ROC AUCs reported in previous stalking violence research (i.e., .87 and .84; Rosenfeld \& Lewis, 2005; Thomas et al., 2008). This is particularly impressive given that a key risk factor (i.e., ex-intimate relationship) was excluded from the current analyses due to a ceiling effect.

The finding that a history of moderate domestic violence, triggering events, and anger were significant across both models suggests that these variables are associated with the occurrence of any stalking violence. However, to help determine whether the violence that ensues is moderate or severe in nature, additional predisposing and contextual factors are required. Interestingly, despite their importance in this research, a history of domestic violence and anger have been infrequently examined in the stalking violence literature and triggering events have not been examined previously.

Despite the fact that many sociocultural and psychological risk factors were significant for severe stalking violence at the bivariate level, only need for control was maintained in the multivariate model. As sociocultural and psychological factors were significantly intercorrelated and significantly correlated with other historical and contextual factors, these correlations may have limited their unique variance. These correlations are not unexpected given that the ITMSV proposes that (a) sociocultural and psychological risk factors are associated with violence across contexts and therefore these variables are likely to be associated with previous acts of violence (b) many of the psychological risk factors are associated with anger and influence stalkers' reactions to high risk situations such as triggering events, and (c) a stalker's sociocultural environment is related to his or her psychological constitution. Consequently, the value of sociocultural and psychological factors may be associated with the mediating and moderating relationships between these variables and historical and contextual factors, rather than their unique variance above and beyond these factors. Future research should examine interactions between sociocultural and psychological risk factors and contextual and historical risk factors using more sophisticated statistical techniques such as Structural Equation Modeling. This was beyond the scope of this research. 
RUNNING HEAD: Are different risk factors associated with moderate and severe stalking violence?

However, even without analyzing interactions and mediating and moderating variables in this study, a better understanding of stalking violence was attained through simple combinations of predisposing and contextual risk factors.

\section{Sex Considerations}

Although the sex of the relational stalker was not a focus of the present study, there are three sex-related findings that deserve further discussion. First, in this study females and males perpetrated similar rates of stalking. This finding is consistent with previous research that has examined stalking using comparable methodologies, including (a) examining stalking without a requirement of fear (b) in samples of university students or community members, and (c) in the context of relationship terminations and/or pursuits (e.g., Cupach \& Spitzberg, 2000; Langhinrichsen-Rohling et al., 2000; Sinclair \& Frieze, 2005; Spitzberg, Nicastro, \& Cousins, 1998). Although research using victim and legally-defined samples typically comprise disproportionate numbers of male stalkers and female victims (e.g., James \& Farnham 2003, Thomas et al. 2008), it has been argued that female-to-male stalking may be under-estimated in victim and legally-defined samples because males are less likely to (a) report stalking behavior to the police (e.g., Bjerregaard, 2000), (b) self-identify as stalking victims (Tjaden et al., 2000; Williams, Frieze, \& Sinclair, 2007), and (c) experience and/or report feeling fearful (e.g., Budd, Mattinson, \& Myhill, 2000; Williams, et al., 2007). Therefore, differences in the distribution of sex may be expected across these types of legal and non-legal sample sources.

Second, male and female stalkers perpetrated similar rates of severe violence and female stalkers perpetrated nearly twice as much moderate violence as their male counterparts. While few studies have differentiated moderate and severe violence, previous research has reported similar rates of severe violence across sex (Sheridan \& Roberts, 2011; Sinclair \& Frieze 2000) and trends towards females perpetrating higher rates of moderate violence (see Thompson et al., 2012; Sinclair \& Frieze 2000). Although Sheridan \& Roberts (2011) reported similar rates of moderate violence across sex, these differences may be attributed to different 
definitions of violence. As mentioned previously, Sheridan and Robert's definition of moderate violence may have captured behaviors that would have been classified as severe violence in both the present study and Sinclair and Frieze's study.

Third, as the majority of participants were female in this research, the majority of relational stalkers and violent stalkers were female, regardless of the relationship between sex and these factors. Consequently, the current findings are primarily applicable to female stalkers, even though controlling for sex did not alter the findings. Given that the ITMSV primarily draws from theoretical frameworks for interpersonal violence developed and empirically tested on males and male perpetrators, the significance of risk factors from this framework in a sample with a disproportionate number of females provides some support for the importance of these factors across sex. Nevertheless, it is important that the present findings are replicated in samples with greater numbers of male participants.

\section{Implications for Prevention and Intervention Strategies}

Although the findings of the present research require replication, these preliminary findings have three implications for prevention and intervention strategies. First, as almost half of the females and nearly one third of the males escalated to violence, prevention and intervention strategies need to be applicable to and validated for females as well as males. Second, much stalking and stalking violence was not reported to the police and thus cannot be addressed using criminal justice responses. Consequently, alternative strategies need to be adopted to disseminate information to targets regarding the risks associated with a stalker's history of DV, warning signs (e.g., threats and revenge motives) and useful strategies to adopt to respond to stalkers to prevent violence (e.g., situational crime prevention strategies).

Third, given the importance of both predisposing and contextual risk factors, intervention and prevention strategies need to address both levels of analysis. Many predisposing risk factors associated with stalking violence are also associated with violence more generally. Consequently, early intervention programs designed to address violence more 
RUNNING HEAD: Are different risk factors associated with moderate and severe stalking violence?

generally may also have preventative benefits across stalking violence, such as interventions that target familial violence and the underlying causes of psychological problems. Courtmandated treatments/programs may also target some of these predisposing risk factors once stalkers have entered the criminal justice system.

Several prevention and intervention strategies may target contextual risk factors. First, as triggering events, such as confrontations, are relatively common coping strategies adopted by targets (Spitzberg, Marshall, \& Cupach, 2001), targets need to be informed of the risks associated with these strategies and alternative strategies should be recommended. Second, targets should be advised to avoid arguments and conflict/disputes with the stalker and to avoid contact with a stalker who is angry or revengeful. Third, interpersonal skills training programs that address deficiencies in coping with triggering events, managing anger or responding to anger-eliciting stimuli and the dissolution of relationships may be useful intervention strategies for stalkers. Fourth, alcohol and illicit drug use can be targeted through (a) advising targets that, if possible, they should avoid contact with a stalker who is under the influence of drugs and/or alcohol and (b) delivering offender intervention strategies that target substance use issues to minimise the risk of future violence. Importantly, all of these suggestions are tentative. Research needs to be conducted to identify which strategies are effective in addressing predisposing and contextual risk factors for stalking violence.

\section{Implications for Risk Assessments}

The present study has six implications for the development of risk assessment tools for stalking violence. First, stalking violence risk assessments must differentiate between moderate and severe stalking violence. Second, stalking violence risk assessments must include both predisposing and contextual risk factors. Third, as the risk of violence fluctuates according to contextual factors, risk assessments need to be dynamic and regularly reassessed. Fourth, stalking violence risk assessments need to be validated for both male and female stalkers. Fifth, moderate violence may be more difficult to predict than severe violence 
RUNNING HEAD: Are different risk factors associated with moderate and severe stalking violence?

given that moderate stalking violence is associated with fewer predisposing risk factors and may be largely associated with contextual risk factors that can fluctuate over time. Sixth, this research identifies new risk factors that may be considered for inclusion in risk assessments, including violent families of origin, violent friends, violent relational entitlement, need for control, severity of stalkers' histories of violence, and triggering events.

\section{Limitations and Directions for Future Research}

The findings in this study need to be interpreted according to the limitations of the research. First, although the ITMSV specifies theoretically-driven mechanisms that account for how risk factors exert their influence, this study aimed to investigate whether a relationship actually existed between these factors and stalking violence as a precursor to comprehensive examinations of the mechanisms that underpin such associations. Moreover, although the model proposes that predisposing and contextual factors interact to cause moderate and severe stalking violence, investigations of these interactions were beyond the scope of this study. Future research should examine the causal mechanisms underlying the effects of individual risk factors, as well as examining how these risk factors interact to best predict moderate and severe stalking violence.

Second, although the use of a standardized tool to measure stalking violence was a strength of this study, the definition of severe violence according to this tool may be less severe than that measured in previous stalking violence research which is typically contingent on violence inflicting injuries (e.g., James \& Farnham, 2003; Sheridan \& Roberts, 2011). Third, there were high rates of missing data for need for control and, because this scale assesses participants' controlling behavior in relationships in the preceding 6 months, it is unclear whether similar scores would have been attained when participants perpetrated stalking behaviors. To avoid these limitations, future research should measure stalkers’ need for control across relationships. Fourth, the current sample is unlikely to be representative of relational stalkers in the community. The current sample was relatively young, highly 
educated, and comprised a disproportionately small number of males. Consequently, these findings should be replicated in a more representative community sample. Fifth, the proportion of stalking in this study that could be prosecuted as unlawful stalking is unknown. This is due to the complexities of simulating legislative criteria in self-report perpetration studies (see Thompson \& Dennison 2008). Replication of these findings in samples of convicted stalkers is necessary to establish generalizability.

Sixth, the present sample was restricted to stalking that occurred after the dissolution of an intimate relationship or in the pursuit of a relationship. It is possible that the current findings are applicable to relational stalking, particularly ex-partner stalking, but not necessarily stalking in other contexts. For example, a history of domestic violence and violent relational entitlement may be less relevant in a sample of non-relational stalking cases. Future research should examine risk factors from the ITMSV in samples of non-relational stalking. Seventh, this study analyzed risk factors for stalking violence using retrospective self-reports. Although retrospective self-reports are the most common methodology used to test criminological theories, and the only way to assess certain variables (see Junger-Tas \& Marshall, 1999), the accuracy of the data is limited by participants' willingness to report antisocial behavior as well as their ability to accurately recall the details of such events. The present study used several strategies to maximize both willingness to report and accuracy of recall, including (a) the questionnaire was both anonymous and completed in privacy (b) the questions normalized antisocial behavior (e.g., "it is normal for people to act out of the ordinary or not be themselves when...”), and (c) a context was provided around many questions to provide an anchor for participants' memories. Nevertheless, replicating this research in samples of convicted stalkers will bolster the findings.

\section{Conclusions}

The current findings support key propositions from the ITMSV. First, severely violent stalkers were characterized by a greater number, and more severe types, of predisposing 
RUNNING HEAD: Are different risk factors associated with moderate and severe stalking violence?

factors than moderately violent or non-violent stalkers. Second, there were risk factors across all three types of contextual factors associated with both moderate and severe stalking violence. Third, combining predisposing and contextual factors resulted in a better understanding of both moderate and severe stalking violence. These findings emphasize the need for stalking violence research to continue examining both predisposing and contextual risk factors and to investigate the causes of moderate and severe stalking violence separately. Furthermore, the finding that females perpetrated higher rates of moderate violence than males and comparable rates of severe violence demonstrates the necessity for theoretical frameworks, risk assessments, and intervention strategies to be applicable across male and female stalkers. Given the support for the individual factors from the ITMSV, future research should examine how risk factors derived from this model may interact to cause stalking violence. Together, this will contribute towards a more sophisticated understanding of the causes of stalking violence and subsequently, facilitate the development of preventative strategies. 


\section{References}

Baum, K., Catalano, S., Rand, M., \& Rose, K. (2009). Stalking victimization in the United States. (NCJ 224527) Washington, DC: U.S Department of Justice, Bureau of Justice Statistics. Retrieved from http://www.ojp.usdoj.gov/bjs/pub/pdf/svus.pdf

Benda, B., \& Toombs, N. (2002). Two preeminent theoretical models: A proportional hazard rate analysis of recidivism. Journal of Criminal Justice, 30, 217-228.

Bernburg, J. G., \& Thorlindsson, T. (1999). Adolescent violence, social control, and the subculture of delinquency: Factors related to violent behavior and non-violent delinquency. Youth \& Society, 30, 445-460.

Bjerregaard, B. (2000). An empirical study of stalking victimization. Violence and Victims, 15, 389- 406.

Bjorklund, K., Hakkanen-Nyholm, H.,Sheridan, L., \& Roberts, K. (2010). The prevalence of stalking among Finnish university students. Journal of Interpersonal Violence, 25, 684-698.

Brennan, K. A., Clark, C. L., \& Shaver, P. R. (1998). Self-report measurement of adult attachment: An integrative overview. In J. A. Simpson \& W. S. Rholes (Eds.), Attachment theory and close relationships (pp. 46-76). New York: Guilford Press.

Brewster, M. P. (2000). Stalking by former intimates: Verbal threats and other predictors of physical violence. Violence and Victims, 15, 41-54.

Brewster, M. P. (2003). Power and control dynamics in prestalking and stalking situations. Journal of Family Violence, 18, 207-217.

Budd, T., Mattinson, J., \& Myhill, A. (2000). The extent and nature of stalking: Findings from the 1998 British Crime Survey: Home Office Research, Development and Statistics Directorate.

Bushman, B., \& Baumeister, R. (1998). Threatened egotism, narcissism, self-esteem, and direct and displaced aggression: Does self-love or self-hate lead to violence? Journal of Personality and Social Psychology, 75, 219-229.

Campbell, J. C., Webster, C. D., Koziol-McLain, J., Block, C., Campbell, D., Curry, M. A., ...Laughon, K. (2003). Risk factors for femicide in abusive relationships: Results from a multisite case control study. American Journal of Public Health, 93, 1089-1097.

Canter, D. V., \& Ioannou, M. (2004). A multivariate model of stalking behaviours. Behaviormetrika, 31, 113-130.

Caplan, M., Vespo, J., Pedersen, J., \& Hay, D. F. (1991). Conflict and its resolution in small groups of one-and two year olds. Child Development, 62, 1513-1524. 
Cassidy, M. A. (1995). Power-control theory: Its potential application to woman battering. Journal of Criminal Justice, 18, 1-15.

Cohen, L. E., \& Felson, M. (1979). Social change and crime rate trends: A routine activities approach. American Sociological Review, 44, 588-608.

Cooksey, R. W. (2007). Illustrating statistical procedures: For business, behavioral and social science research. Prahan, VIC: Tilde University Press.

Cornish, D. B., \& Clarke, R. V. (2003). Opportunities, precipitators and criminal decisions: A reply to Wortley's critique of situational crime prevention. Crime Prevention Studies, 16, 41-96.

Cupach, W. R., \& Spitzberg, B. H. (2000). Obsessive relational intrusion: Incidence, perceived severity, and coping. Violence and Victims, 15, 357-372.

Davis, K. E., Ace, A., \& Andra, A. (2000). Stalking perpetrators and psychological maltreatment of partners: Anger-jealousy, attachment insecurity, need for control, and break-up context. Violence and Victims, 15, 407-425.

Dennison, S. M. (2007). Interpersonal relationships and stalking: Identifying when to intervene. Law and Human Behavior, 31, 353-367.

Dutton, L. B., \& Winstead, B. A. (2006). Predicting unwanted pursuit: Attachment, relationship satisfaction, relationship alternatives, and break-up distress. Journal of Social and Personal Relationships, 23, 565-586.

Farnham, F. R., James, D. V., \& Cantrell, P. (2000). Association between violence, psychosis, and relationship to victim in stalkers. The Lancet, 355, 199.

Follingstad, D. R., Bradley, R. G., Helff, C., \& Laughlin, J. E. (2002). A model for predicting dating violence: Anxious attachment, angry temperament, and need for relationship control. Violence and Victims, 17, 35-47.

Follingstad, D. R., Bradley, R. G., Laughlin, J. E., \& Burke, L. (1999). Risk factors and correlates of dating violence: The relevance of examining frequency and severity levels in a college sample. Violence and Victims, 14, 365-380.

Foshee, V. A., Bauman, K. E., \& Linder, G. F. (1999). Family violence and the perpetration of adolescent dating violence: Examining social learning and social control processes. Journal of Marriage and the Family, 61, 331-342.

Giancola, P. R. (2002). Alcohol related aggression in men and women: The influence of dispositional aggressivity. Journal of Studies on Alcohol and Drugs, 63, 696-708.

Giancola, P. R., Saucher, D. A., \& Gussler-Burkhardt, N. L. (2003). The effects of affective, 
behavioral, and cognitive components of trait anger on the alcohol-aggression relation. Alcoholism: Clinical and Experimental Research, 27, 1944-1954.

Gilchrist, E. (2009). Implicit thinking about implicit theories in intimate partner violence Psychology, Crime \& Law, 15, 131-145.

Goldenson, J., Geffner, R., Foster, S. L., \& Clipson, C. R. (2007). Female domestic violence offenders: Their attachment security, trauma symptoms, and personality organization. Violence and Victims, 22, 532-545.

Guerrero, L. K., Andersen, P. A., Jorgensen, P. F., Spitzberg, B. H., \& Eloy, S. V. (1995). Coping with the green-eyed monster: Conceptualizing and measuring communicative responses to romantic jealousy. Western Journal of Communication, 59, 270-304.

Harmon, R. B., Rosner, R., \& Owens, H. (1998). Sex and violence in a forensic population of obsessional harassers. Psychology, Public Policy and Law, 4, 236-249.

Holtzworth-Munroe, A., \& Meehan, J. C. (2004). Typologies of men who are maritally violent: Scientific and clinical implications. Journal of Interpersonal Violence, 19, 1369-1389.

Holtzworth-Munroe, A., \& Stuart, G. L. (1994). Typologies of male batterers: Three subtypes and the differences among them. Psychological Bulletin, 116, 476-497.

Hyler, S. E. (1994). PDQ-4 Personality Questionnaire. New York: Unpublished scale: New York State Psychiatric Institute.

Indermaur, D. (1996). Reducing the opportunities for violence in robbery and property crime: The perspectives of offenders and victims. Crime Prevention Studies, 5, 133-157.

Jaccard, J., \& Wan, C. K. (1996). LISREL approaches to interaction effects in multiple regression. Thousand Oaks, CA: Sage Publications.

James, D. V., \& Farnham, F. R. (2003). Stalking and serious violence. The Journal of the American Academy of Psychiatry and the Law, 31, 432-439.

Junger-Tas, J., \& Marshall, I.H. (1999). The self-report methodology in crime research. Crime and Justice, 25, 291-367.

Kienlen, K. K., Birmingham, D. L., Solberg, K. B., O'Regan, J. T., \& Meloy, J. R. (1997). A comparative study of psychotic and nonpsychotic stalking. Journal of the American Academy of Psychiatry and Law, 25, 317-334.

Knapp, H., \& Kirk, S. A. (2003). Using pencil and paper, internet, and touch-tone phones for self-administered surveys: Does methodology matter? Computers in Human Behavior, 19, 117-134. 
Langhinrichsen-Rohling, J., Palarea, R. E., Cohen, J., \& Rohling, M. L. (2000). Breaking up is hard to do: Unwanted pursuit behaviors following the dissolution of a romantic relationship. Violence and Victims, 15, 73 - 90.

Marshall, W. L., \& Barbaree, H. E. (1990). An integrated theory of the etiology of sexual offending. In W. L. Marshall, D. R. Laws \& H. E. Barbaree (Eds.), Handbook of sexual assault: Issues, theories and treatment of the offender (pp. 257-275). New York: Plenum Press.

Mazerolle, P. (1999). Omaha Intimate Partner Violence Study: Final Report. Cincinnati, Ohio.

McCann, J. T. (2001). The relationship between threats and violence in juvenile stalking. Journal of Threat Assessment, 1(3), 81-90.

McClellan, A. C., \& Killeen, M. (2000). Attachment theory and violence towards women by male intimate partners. Journal of Nursing Scholarships, 32, 353-360.

McEwan, T., Mullen, P. E., MacKenzie, R.D., \& Ogloff, J.R.P. (2009). Violence in stalking situations. Psychological Medicine, 39, 1469-1478.

McKenry, P. C., Julian, T., \& Gavazzi, S. M. (1995). Toward a biopsychosocial model of domestic violence. Journal of Marriage and Family, 57, 307-320.

McMurran, M. (2007). The relationship between alcohol-aggression proneness, general alcohol expectancies, hazardous drinking, and alcohol-related violence in adult male prisoners. Psychology, Crime \& Law, 13, 275-284.

Meloy, J. R. (1997). The clinical risk management of stalking: "Someone is watching over me...". American Journal of Psychotherapy, 51, 174-184.

Meloy, J. R., \& Boyd, C. (2003). Female stalkers and their victims. Journal of the American Academy of Psychiatry and Law, 31, 211-219.

Meloy, J. R., Davis, B., \& Lovette, J. (2001). Risk factors for violence among stalkers. Journal of Threat Assessment, 1(1), 3-16.

Melton, H. C. (2007). Predicting the occurrence of stalking in relationships characterized by domestic violence. Journal of Interpersonal Violence, 22, 3-25.

Menzies, R. P. D., Fedoroff, J. P., Green, C. M., \& Isaacson, K. (1995). Prediction of dangerous behaviour in male erotomania. British Journal of Psychiatry, 166, 529-536.

Moffitt, T. E. (1993). Adolescence-limited and life-course-persistent antisocial behavior: A developmental perspective. Psychological Review, 4, 674-701.

Mohandie, K., Meloy, J. R., Green McGowan, M., \& Williams, J. (2006). The RECON typology of stalking: Reliability and validity based upon a large sample of North American stalkers. Journal of Forensic Sciences, 51, 147-155. 
RUNNING HEAD: Are different risk factors associated with moderate and severe stalking violence?

Morrison, K. A. (2001). Predicting violent behavior in stalkers: A preliminary investigation of Canadian cases in criminal harassment. Journal of Forensic Sciences, 46, 1403-1410.

Morrison, K. A. (2008). Differentiating between physically violent and nonviolent stalkers: An examination of Canadian cases. Journal of Forensic Sciences, 53, 742751.

Mullen, P. E., Pathe, M., Purcell, R., \& Stuart, G. W. (1999). Study of stalkers. American Journal of Psychiatry, 156, 1244-1249.

Norris, S.M., Huss, M.T., \& Palarea, R.E. (2011). A pattern of violence: Analyzing the relationship between intimate partner violence and stalking. Violence and Victims, 26, 103- 115.

Ogilvie, E. (2000). Stalking: Legislative, policing and prosecuting practices in Australia. Canberra: Australian Institute of Criminology.

Palarea, R. E., Zona, M. A., Lane, J., \& Langhinrichsen-Rohling, J. (1999). The dangerous nature of intimate relationship stalking: Threats, violence and associated risk factors. Behavioral Sciences and the Law, 17, 269-283.

Pan, H. S., Neidig, P. H., \& O'Leary, K. D. (1994). Predicting mild and severe husband-towife physical aggression. Journal of Consulting and Clinical Psychology, 62, 975-981.

Pathe, M., \& Mullen, P. E. (1997). The impact of stalkers on their victims. British Journal of Psychiatry, 170, 12-17.

Patterson, G. R., Shaw, D. S., Snyder, J. J., \& Yoerger, K. (2001). Changes in maternal ratings of children's overt and covert antisocial behavior. Aggressive Behavior, 31, 473-484.

Prinstein, M. J., Boergers, J., \& Spirito, A. (2001). Adolescents' and their friends' health-risk behavior: Factors that alter or add to peer influence. Journal of Pediatric Psychology, 26, 287-298.

Purcell, R., Pathe, M., \& Mullen, P. E. (2000). The incidence and nature of stalking victimisation. Paper presented at the Stalking: Criminal Justice Responses Conference, Sydney.

Purcell, R., Pathe, M., \& Mullen, P. E. (2002). The prevalence and nature of stalking in the Australian community. Australian and New Zealand Journal of Psychiatry, 36, 114120.

Purcell, R., Powell, M. B., \& Mullen, P. E. (2005). Clients who stalk psychologists: Prevalence, methods, and motives. Professional Psychology, Research and Practice., 36(5), 537-543. 
RUNNING HEAD: Are different risk factors associated with moderate and severe stalking violence?

Putninš, A. (2005). Secure Care Psychosocial Screening: Manual for SECAPS v. 5. South Australia: Youth Justice Branch: Children Youth and Family Services.

Roberts, K. A. (2005). Women's experience of violence during stalking by former romantic partners: Factors predictive of stalking violence. Violence Against Women, 11, 89-114.

Rosenfeld, B. (2004). Violence risk factors in stalking and obsessional harassment: A review and preliminary meta-analysis. Criminal Justice and Behavior, 31, 9-36.

Rosenfeld, B., \& Harmon, R. B. (2002). Factors associated with violence in stalkers and obsessional harassment cases. Criminal Justice and Behavior, 29, 671-691.

Rosenfeld, B., \& Lewis, C. (2005). Assessing violence risk in stalking cases: A regression tree approach. Law and Human Behavior, 29, 343-357.

Runge, M. M. (2005). An interplay between dispositional and situational factors: Intrapersonal models of relationship violence. Unpublished $\mathrm{PhD}$, University of South Carolina, South Carolina.

Samuel, D. B., \& Widiger, T. A. (2008). Convergence of narcissism measures from the perspective of general personality functioning. Assessment, 15, 364-374.

Schwartz-Watts, D., \& Morgan, D. W. (1998). Violent versus non-violent stalkers. Journal of the American Academy of Psychiatry and Law, 26, 241-245.

Sheridan, L., \& Davies, G. M. (2001). Violence and the prior victim-stalker relationship. Criminal Behaviour and Mental Health, 11, 102-116.

Sheridan, L., Davies, G. M., \& Boon, J. (2001). The course and nature of stalking: A victim perspective. The Howard Journal, 40, 215-234.

Sheridan, L., \& Roberts, K. (2011). Key Questions to Consider in Stalking Cases. Behavioral Sciences and the Law, 29, 255-270.

Sinclair, H. C., \& Frieze, I. H. (2000). Initial courtship behavior and stalking: How should we draw the line? Violence and Victims, 15, 23 - 40.

Sinclair, H. C., \& Frieze, I. H. (2005). When courtship persistence becomes intrusive pursuit: Comparing rejecter and pursuer perspectives of unrequited attraction. Sex Roles, 52, 839-852.

Spitzberg, B.H., \& Cupach, W.R. (1997). Relational pursuit: Pursuer Short Form. Unpublished measure.

Spitzberg, B.H., \& Cupach, W.R. (2007). The state of the art of stalking: Taking stock of the emerging literature. Aggression and Violent Behavior, 12, 64-86.

Spitzberg, B. H., Marshall, L. E., \& Cupach, W. R. (2001). Obsessive relational intrusion, coping, and sexual coercion victimization. Communication Reports, 14, 19-30. 
Spitzberg, B. H., Nicastro, A. M., \& Cousins, A. V. (1998). Exploring the interactional phenomenon of stalking and obsessive relational intrusion. Communication Reports, $11,33-47$.

Straus, M. A., Hamby, S. L., Boney-McCoy, S., \& Sugarman, D. B. (1996). The revised conflict tactics scale (CTS2): Development and preliminary psychometric data. Journal of Family Issues, 17, 283-316.

Tabachnick, B. G., \& Fidell, L. S. (2001). Using multivariate statistics (4th ed.). Boston: Allyn and Bacon.

Thomas, S. D. M., Purcell, R., Pathe, M., \& Mullen, P. E. (2008). Harm associated with stalking victimization. Australian and New Zealand Journal of Psychiatry, 42, 800806.

Thompson, C. M. (2009). Developing and testing an integrated theoretical model of stalking violence. (Doctoral dissertation). Available from Australasian Digital Theses Program. (Record No. 280553). Available from; http://www4.gu.edu.au:8080/adtroot/public/adt-QGU20100526.150128/index.html

Thompson, C. M., \& Dennison, S. M. (2008). Defining relational stalking in research:

Understanding sample composition in relation to repetition and duration of harassment. Psychiatry, Psychology and Law, 15, 482-499.

Thompson, C. M., Dennison, S. M., \& Stewart, A. (2012). Are female stalkers more violent than male stalkers? Understanding gender differences in stalking violence using contemporary sociocultural beliefs. Sex Roles, 66, 351-365.

Thompson, C. M., \& Stewart, A. (2011). Assessing risk of reoffending. In A. Stewart, T. Allard and S. Dennison (Eds.), Evidence based policy and practice in youth justice (pp. 116- 133). Australia: The Federation Press.

Thompson, M., Saltzman, L., \& Johnson, H. (2001). Risk factors for physical injury among women assaulted by current or former spouses. Violence Against Women, 7, 886-899.

Tjaden, P., Thoennes, N., \& Allison, C. J. (2000). Comparing stalking victimization from legal and victim perspectives. Violence and Victims, 15, 7-22.

Tremblay, R., \& Nagin, D. (2005). The developmental origins of physical aggression in humans. In R. Tremblay, W. W. Hartup \& J. Archer (Eds.), Developmental origins of aggression (pp. 83-106). New York: The Guilford Press.

Wang, E. W., \& Diamond, P. M. (1999). Empirically identifying factors related to violence risk in corrections. Behavioral Sciences and the Law, 17, 377-389. 
RUNNING HEAD: Are different risk factors associated with moderate and severe stalking violence?

White, J., Kowlaski, R. M., Lyndon, A., \& Valentine, S. (2000). An integrative contextual model of male stalking. Violence and Victims, 15, 373-388.

Wilkinson, D. L., \& Hamerschlag, S. J. (2005). Situational determinants in intimate partner violence. Aggression and Violent Behavior, 10, 333-361.

Williams, S. L., Frieze, I. H., \& Sinclair, H. C. (2007). Intimate stalking and partner violence. In J. Hamel \& T. Nicholls (Eds.), Family interventions in domestic violence: A handbook of gender-inclusive theory and treatment (pp. 109-123). New York: Springer Publishing Company.

Wortley, R. (2001). A classification of techniques for controlling situational precipitators of crime. Security Journal, 14, 63-82.

Zahn-Waxler, C., Friedman, R. J., Cole, P. M., Mizuta, I., \& Hiruma, N. (1996). Japanese and United States preschool children's responses to conflict and distress. Child Development, 67, 2462-2477. 
RUNNING HEAD: Are different risk factors associated with moderate and severe stalking violence?

Table 1

Summary of Findings for Risk Factors for Stalking Violence

\begin{tabular}{|l|l|l|l|l|l|l|l|l|l|l|l|l|}
\hline First Author (Year) & Crim & VHx & DV & SA & SU & PD & Psy & I & Thrt & Ex & Rvg & Appr \\
\hline Bjorklund (2010) & & & & & & & & & $\checkmark$ & $\mathbf{x}$ & & \\
\hline Brewster (2000, 2003) & & & $\mathbf{x}$ & $\checkmark$ & & & & & $\checkmark$ & & & \\
\hline Canter (2004) & & & & & & & & & $\checkmark$ & $\checkmark$ & & \\
\hline Harmon (1998) & $\checkmark$ & & & $\checkmark$ & & $\checkmark$ w-c & & & $\checkmark$ & $\checkmark$ & $\mathbf{x}$ & \\
\hline Kienlen (1997) & & & & & & & $\mathbf{x}$ & & & & & \\
\hline McCann (2001) & & & & & & & & & $\mathbf{x}$ & & & \\
\hline McEwan (2009) & & $\checkmark$ & & & $\checkmark$ n-r & & $\checkmark$ & & $\checkmark$ r & & & \\
\hline Meloy (2001) & $\mathbf{x}$ & & & $\mathbf{x}$ & & $\mathbf{x}$ & & $\checkmark$ & $\checkmark$ & $\checkmark$ & & \\
\hline Meloy (2003) & & & & & & & & & $\checkmark$ & $\checkmark$ & & \\
\hline Menzies (1995) & & & & $\mathbf{x}$ & & $\mathbf{x}$ & & & & & & \\
\hline Mohandie (2006) & & & & & & & $\checkmark$ & & & $\checkmark$ & & \\
\hline Morrison (2001) & & $\checkmark$ & $\checkmark$ & & & & & $\checkmark$ & $\checkmark$ & & & \\
\hline Morrison (2008) & $\mathbf{x}$ & & $\checkmark$ & $\mathbf{x}$ & & $\mathbf{x}$ & & $\mathbf{x}$ & $\checkmark$ & & & \\
\hline Mullen (1999) & $\checkmark$ & & & $\checkmark$ & & & $\checkmark$ & & $\checkmark$ & $\checkmark$ & & \\
\hline Palarea (1999) & $\mathbf{x}$ & $\checkmark$ & $\mathbf{x}$ & & & & & $\mathbf{x}$ & $\checkmark$ & $\checkmark$ & & $\checkmark$ \\
\hline Purcell (2005) & & & & & & & & $\mathbf{x}$ & $\checkmark$ & & $\mathbf{x}$ & \\
\hline Roberts (2005) & & & $\mathbf{x}$ & $\checkmark$ & & & & $\mathbf{x}$ & $\checkmark$ & & & \\
\hline Rosenfeld (2002) & $\mathbf{x}$ & $\mathbf{x}$ & & $\checkmark$ & & $\mathbf{x}$ & $\checkmark$ & & $\checkmark$ & $\checkmark$ & $\checkmark$ & \\
\hline Schwartz-Watt5(1998) & & & & $\mathbf{x}$ & & & $\mathbf{x}$ & $\mathbf{x}$ & & $\mathbf{x}$ & & \\
\hline Sheridan (2001) & & & & & & & & & $\checkmark$ & $\checkmark$ & & \\
\hline Thomas (2008) & & & & & & & & $\checkmark$ & $\checkmark$ & $\checkmark$ & & $\checkmark$ \\
\hline James (2003) & $\checkmark$ Op. & $\mathbf{x}$ & & $\mathbf{x}$ & $\mathbf{x}$ & $\mathbf{x}$ & & & $\checkmark$ & $\checkmark$ & & $\checkmark$ \\
\hline Farnham (2000) & & & & & & & $\mathbf{x}$ & & & $\checkmark$ & & \\
\hline Sheridan (2011) & & $\checkmark$ & mod & $\checkmark$ & & & & & $\checkmark$ mod & $\mathbf{x}$ & & $\checkmark$ \\
\hline
\end{tabular}

Note. $\checkmark=$ significant; $\boldsymbol{x}=$ non-significant; empty cell = not investigated; Highlighted rows = severe violence; Crim= criminal history; VHx = history of violence; DV = History of domestic violence; SA = Substance abuse; $\mathrm{SU}=$ substance use at time of stalking; $\mathrm{PD}=$ Personality disorder; Psy = Absence of psychosis; $\Psi=$ Any/other mental; illness; Thrt = Threats; Ex = Ex-Intimate Relationship; Rvg = Revenge motives; Appr = Approach behaviors; Op. = Finding was the opposite direction to other research; $\mathrm{w}-\mathrm{c}=$ with comorbidity; $\bmod =$ significant for moderate violence; $\mathrm{n}-\mathrm{r}=$ significant for non-rejected typologies only; $\mathrm{r}$ = significant for rejected typology only. 
Predisposing Factors

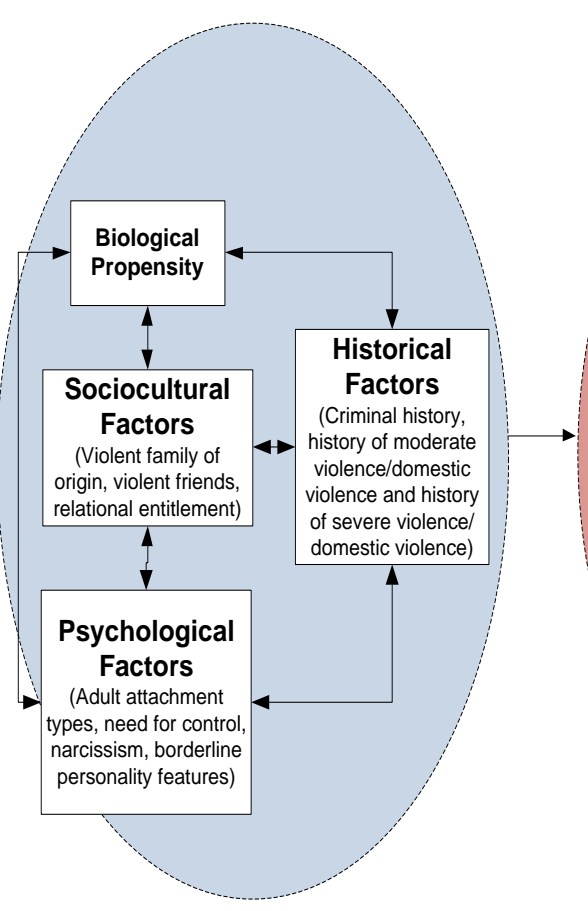

Contextual Factors

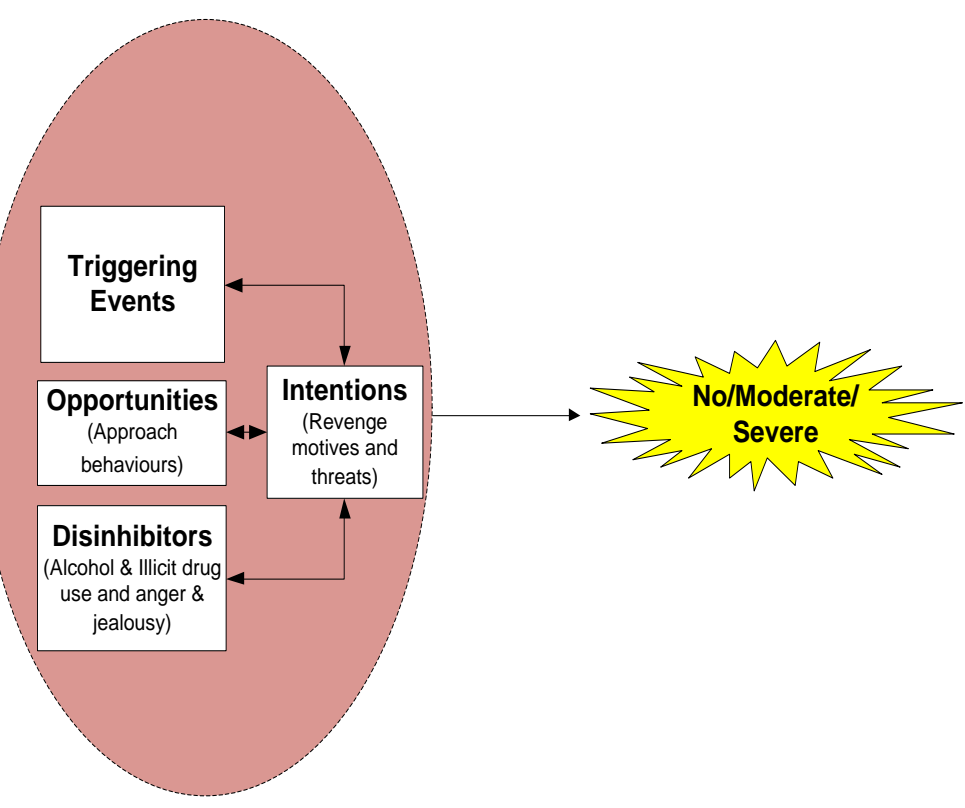

Figure 1. The ITMSV, with example risk factors in brackets. 
RUNNING HEAD: Are different risk factors associated with moderate and severe stalking violence?

Table 2

Distribution of Stalking Violence across Predisposing Risk Factors

\begin{tabular}{|c|c|c|c|c|c|}
\hline Risk factor & & $\begin{array}{r}\text { No } \\
\text { violence } \\
n(\%) \\
\end{array}$ & $\begin{array}{r}\text { Moderate } \\
\text { violence } \\
n(\%) \\
\end{array}$ & $\begin{array}{r}\text { Severe } \\
\text { violence } \\
n(\%) \\
\end{array}$ & $\begin{array}{r}\text { Total } \\
n(\%)^{\mathrm{a}}\end{array}$ \\
\hline Sociocultural & Violent Family of Origin & & & & \\
\hline \multirow[t]{8}{*}{ Factors } & Absent & 298 (60.3)* & $130(26.3)$ & $66(13.4)^{*}$ & $494(100.0)$ \\
\hline & Present & $91(51.7)^{*}$ & $45(25.6)$ & $40(22.7)^{*}$ & $176(100.0)$ \\
\hline & Violent Friends & & & & \\
\hline & Absent & $307(60.6)^{*}$ & 135 (26.6) & $65(12.8)^{*}$ & 507 (100.0) \\
\hline & Present & $84(50.6)^{*}$ & $41(24.7)$ & $41(24.7)^{*}$ & $166(100.0)$ \\
\hline & $\begin{array}{l}\text { Violent relational } \\
\text { entitlement }\end{array}$ & & & & \\
\hline & Unsupportive & 211 (64.1)* & $83(25.2)$ & $35(10.6)^{*}$ & 329 (99.9) \\
\hline & Supportive & $199(53.2)^{*}$ & $101(27.0)$ & $74(19.8) *$ & $374(100.0)$ \\
\hline \multirow{15}{*}{$\begin{array}{l}\text { Psychological } \\
\text { factors }\end{array}$} & Adult Attachment Type & & & & \\
\hline & Secure & $80(61.5)$ & 25 (19.2) & $25(19.2)$ & 130 (99.9) \\
\hline & Fearful & $117(56.0)$ & $56(26.8)$ & $36(17.2)$ & $209(100.0)$ \\
\hline & Pre-Occupied & $193(60.1)$ & $85(26.5)$ & $43(13.4)$ & $321(100.0)$ \\
\hline & Dismissing & $20(46.5)$ & 18 (41.9) & $5(11.6)$ & $43(100.0)$ \\
\hline & Need for Control $^{\mathrm{b}}$ & & & & \\
\hline & $\begin{array}{l}\text { Low Need for } \\
\text { Control }\end{array}$ & $181(61.8)^{*}$ & $79(27.0)$ & $33(11.3)^{*}$ & $293(100.1)$ \\
\hline & $\begin{array}{l}\text { High Need for } \\
\text { Control }\end{array}$ & $115(52.0)^{*}$ & 52 (23.5) & $54(24.4)^{*}$ & 221 (99.9) \\
\hline & Narcissism & & & & \\
\hline & Absent & $342(60.3)^{*}$ & 149 (26.3) & $76(13.4)^{*}$ & $567(100.0)$ \\
\hline & Present & $68(50.0)^{*}$ & $35(25.7)$ & $33(24.3)^{*}$ & $136(100.0)$ \\
\hline & Borderline Personality & & & & \\
\hline & Features & & & & \\
\hline & Absent & $334(62.4)^{*}$ & $132(24.7)$ & $69(12.9)^{*}$ & $535(100.0)$ \\
\hline & Present & $76(45.2)^{*}$ & $52(31.0)$ & $40(23.8)^{*}$ & $168(100.0)$ \\
\hline \multirow{14}{*}{$\begin{array}{l}\text { Historical } \\
\text { factors }\end{array}$} & History of Moderate & & & & \\
\hline & Violence & & & & \\
\hline & Absent & $248(69.3)^{*}$ & $77(21.5)^{*}$ & $33(9.2)^{*}$ & $358(100.0)$ \\
\hline & Present & $162(47.0)^{*}$ & $107(31.0)^{*}$ & $76(22.0)^{*}$ & 345 (100.0) \\
\hline & History of Moderate & & & & \\
\hline & Domestic Violence & & & & \\
\hline & Absent & $341(69.2)^{*}$ & $104(21.1)^{*}$ & $48(9.7)^{*}$ & $493(100.0)$ \\
\hline & Present & 69 (32.9)* & $80(38.1)^{*}$ & $61(29.0)^{*}$ & $210(100.0)$ \\
\hline & $\begin{array}{l}\text { History of Any Severe } \\
\text { violence }\end{array}$ & & & & \\
\hline & Absent & $335(61.4)^{*}$ & $152(27.8)$ & $59(10.8)^{*}$ & $546(100.0)$ \\
\hline & Present & $75(47.8)^{*}$ & $32(20.4)$ & $50(31.8) *$ & $157(100.0)$ \\
\hline & Police Contact $^{\mathrm{b}}$ & & & & \\
\hline & Absent & 395 (59.0) & 178 (26.6) & 96 (14.3) & 669 (99.9) \\
\hline & Present & 15 (44.1) & 6 (17.6) & $13(38.2)$ & 34 (99.9) \\
\hline
\end{tabular}

* Posthoc analyses indicated adjusted residuals exceeded absolute 2.0

${ }^{\text {a }}$ Some totals do not equal $100 \%$ due to rounding

${ }^{\mathrm{b}}$ Inferential statistics not conducted due to low endorsement of item 
RUNNING HEAD: Are different risk factors associated with moderate and severe stalking violence?

Table 3

Distribution of Stalking Violence across Contextual Factors

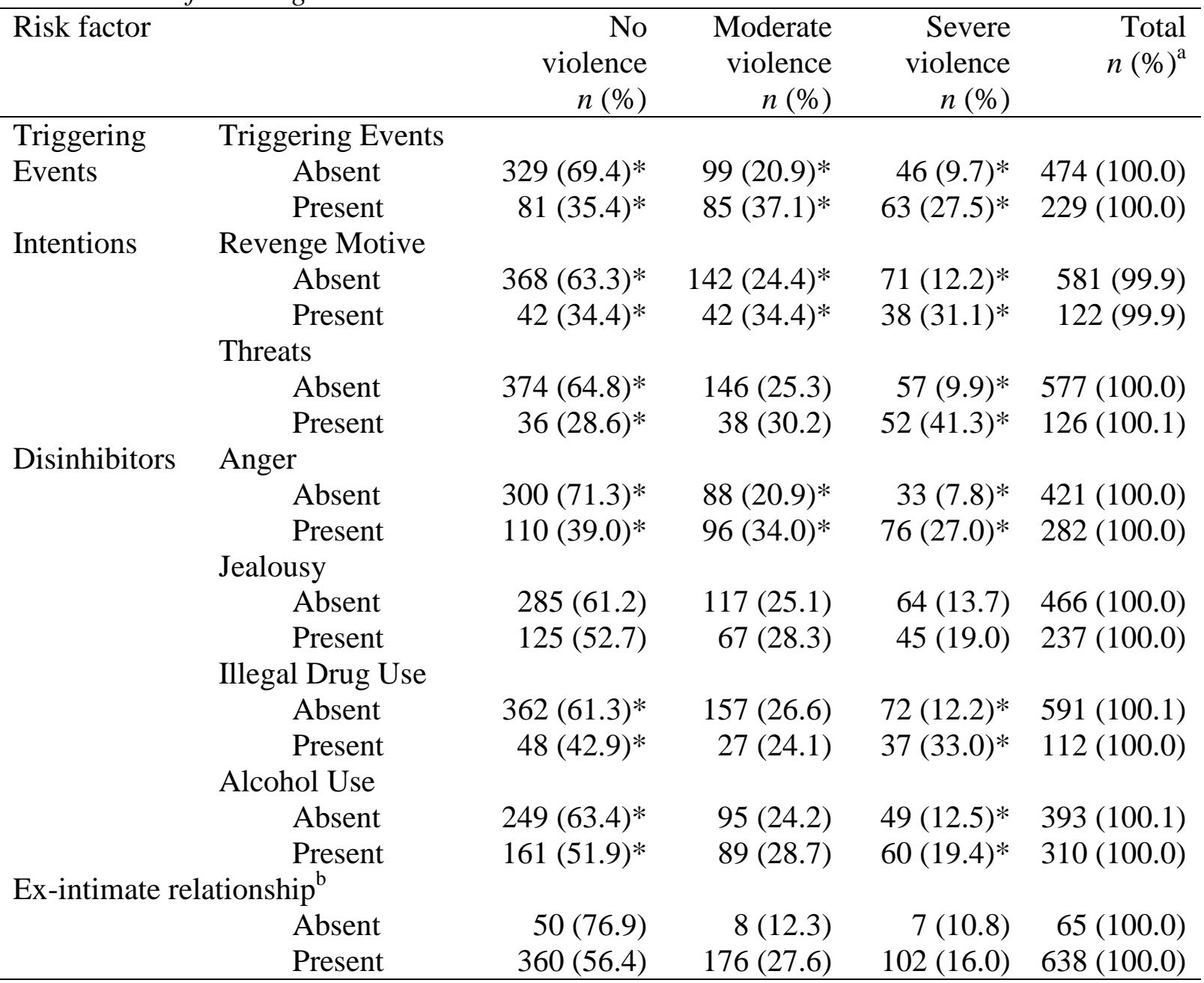

* Posthoc analyses indicated adjusted residuals exceeded absolute 2.0

${ }^{\text {a }}$ Some totals do not equal $100 \%$ due to rounding

${ }^{\mathrm{b}}$ Inferential statistics not conducted due to low endorsement of item 
RUNNING HEAD: Are different risk factors associated with moderate and severe stalking violence?

Table 4

Logistic Regression Results for No Stalking Violence versus Moderate Stalking Violence

\begin{tabular}{|c|c|c|c|c|c|}
\hline \multirow[b]{2}{*}{ Variables } & \multirow[b]{2}{*}{$B(\mathrm{SE})$} & \multirow[b]{2}{*}{$\begin{array}{l}\text { Wald Test } \\
\text { (z ratio) }\end{array}$} & \multirow[b]{2}{*}{$\begin{array}{l}\text { Odd } \\
\text { Ratio }\end{array}$} & \multicolumn{2}{|c|}{$\begin{array}{l}\text { 95\% Confidence } \\
\text { Interval for Odds } \\
\text { Ratio }\end{array}$} \\
\hline & & & & Lower & Upper \\
\hline Sex & $0.46(0.27)$ & 2.91 & 1.59 & 0.93 & 2.71 \\
\hline $\begin{array}{l}\text { History of moderate } \\
\text { violence }\end{array}$ & $0.34(0.22)$ & 2.49 & 1.41 & 0.92 & 2.15 \\
\hline $\begin{array}{l}\text { History of moderate } \\
\text { domestic violence }\end{array}$ & $1.18(0.23)$ & $25.93^{*}$ & 3.26 & 2.07 & 5.14 \\
\hline Revenge motive & $0.49(0.28)$ & 3.04 & 1.63 & 0.94 & 2.83 \\
\hline Triggering events & $0.99(0.22)$ & $19.57 *$ & 2.69 & 1.73 & 4.16 \\
\hline Anger & $0.69(0.22)$ & $9.88 *$ & 2.00 & 1.30 & 3.07 \\
\hline
\end{tabular}

$* \leq .002$ 
RUNNING HEAD: Are different risk factors associated with moderate and severe stalking violence?

Table 5

Logistic Regression Models for No Violence versus Severe Violence

\begin{tabular}{|c|c|c|c|c|c|c|}
\hline Model & Variables & $B(\mathrm{SE})$ & Wald Test & $\begin{array}{l}\text { Odd } \\
\text { Ratio }\end{array}$ & \multicolumn{2}{|c|}{$(95 \% \mathrm{CI})$} \\
\hline Predisposing & History moderate DV & $1.50(0.29)$ & $26.89 * *$ & 4.47 & 2.54 & 7.88 \\
\hline \multirow[t]{8}{*}{ Risk Factors } & History moderate violence & $0.41(0.33)$ & 1.57 & 1.51 & 0.79 & 2.88 \\
\hline & History severe violence & $0.70(0.32)$ & $4.94 *$ & 2.02 & 1.09 & 3.74 \\
\hline & Violent relational entitlement & $0.66(0.30)$ & $5.03^{*}$ & 1.94 & 1.09 & 3.45 \\
\hline & Violent friends & $0.43(0.31)$ & 1.99 & 1.54 & 0.85 & 2.81 \\
\hline & Violent family of origin & $0.33(0.31)$ & 1.17 & 1.39 & 0.77 & 2.53 \\
\hline & Borderline personality & $0.35(0.32)$ & 1.20 & 1.42 & 0.76 & 2.67 \\
\hline & Narcissism & $0.10(0.36)$ & 0.08 & 1.11 & 0.55 & 2.25 \\
\hline & Need for control & $.063(0.29)$ & $4.86^{*}$ & 1.87 & 1.07 & 3.28 \\
\hline Contextual & Threats & $1.70(0.30)$ & $32.31 * *$ & 5.45 & 3.04 & 9.77 \\
\hline \multirow[t]{5}{*}{ Risk Factors } & Revenge motive & $0.32(0.33)$ & 0.93 & 1.38 & 0.72 & 2.64 \\
\hline & Triggering events & $1.11(0.28)$ & $15.80^{* *}$ & 3.05 & 1.76 & 5.28 \\
\hline & Alcohol use & $0.35(0.28)$ & 1.56 & 1.42 & 0.82 & 2.45 \\
\hline & Drug use & $1.01(0.32)$ & $9.81^{* *}$ & 2.74 & 1.46 & 5.16 \\
\hline & Anger & $1.11(0.28)$ & $15.34 * *$ & 3.04 & 1.74 & 5.31 \\
\hline Integrated & History moderate DV & $1.70(0.30)$ & $33.17^{* *}$ & 5.46 & 3.07 & 9.73 \\
\hline Model & History severe violence & $0.70(0.30)$ & $5.48 *$ & 2.02 & 1.12 & 3.65 \\
\hline (without need & Violent relational entitlement & $0.50(0.29)$ & 2.99 & 1.64 & 0.94 & 2.88 \\
\hline \multirow[t]{4}{*}{ for control) } & Threats & $1.68(0.32)$ & $27.98^{* *}$ & 5.39 & 2.89 & 10.06 \\
\hline & Triggering events & $1.28(0.30)$ & $18.53^{* *}$ & 3.61 & 2.01 & 6.48 \\
\hline & Drugs & $0.70(0.33)$ & $4.51 *$ & 2.01 & 1.06 & 3.82 \\
\hline & Anger & $0.98(0.29)$ & $11.21^{* *}$ & 2.66 & 1.50 & 4.70 \\
\hline Integrated & History of moderate DV & $1.56(0.33)$ & $22.32 * *$ & 4.74 & 2.48 & 9.03 \\
\hline Model & History of severe violence & $0.68(0.34)$ & $4.09 *$ & 1.97 & 1.02 & 3.81 \\
\hline (with need & Relational entitlement & $0.46(0.33)$ & 1.97 & 1.58 & 0.83 & 2.99 \\
\hline \multirow[t]{5}{*}{ for control) } & Threats & $1.55(0.36)$ & $18.15^{* *}$ & 4.69 & 2.31 & 9.56 \\
\hline & Triggering events & $1.47(0.33)$ & $19.37 * *$ & 4.35 & 2.26 & 8.37 \\
\hline & Drugs & $0.53(0.37)$ & 2.00 & 1.69 & 0.82 & 3.51 \\
\hline & Anger & $0.85(0.33)$ & $6.54 *$ & 2.33 & 1.22 & 4.45 \\
\hline & Need for control & $0.69(0.32)$ & $4.73 *$ & 2.00 & 1.07 & 3.72 \\
\hline
\end{tabular}


Carleen Thompson is a postdoctoral research fellow in the Key Centre for Ethics, Law, Justice and Governance at Griffith University. Her research interests include stalking, interpersonal violence, risk assessment, life-course criminology, criminal careers and workintegrated learning. Carleen has co-developed risk screening tools with Prof Anna Stewart that have been implemented in several jurisdictions across Australia.

Susan Dennison is an Associate Professor in the School of Criminology and Criminal Justice, Griffith University. She is the recipient of a four-year Australian Research Council Future Fellowship to examine the impact of paternal imprisonment on children's developmental outcomes. Other research interests include stalking, developmental life course criminology and juvenile offending trajectories.

Anna Stewart is a professor in the School of Criminology and Criminal Justice, Griffith University, Brisbane, Australia. Her research interests include youth justice, family violence, life course criminology, crime analysis and risk assessment. Recent publications have appeared in Criminology, Sex Roles: A Journal of Research, Australian and New Zealand Journal of Criminology, Journal of Experimental Criminology, and Child Abuse and Neglect. 